\title{
On-Chip Integrated Power Management MPPT Controller Utilizing Cell- Level Architecture for PV Solar System
}

\author{
Mohamed Orabi*, Fatma Hilmy*, Ahmed Shawky*, Jaber A. Abu Qahouq**, El-Sayed Hasaneen* and \\ Eman Goma** \\ *APEARC, Aswan University, Aswan 81542, Egypt \\ **The University of Alabama, Department of Electrical and Computer Engineering, Tuscaloosa, Alabama 35487, \\ USA
}

\begin{abstract}
Corresponding Author:
Mohamed Orabi

APEARC, Aswan University, Aswan 81542, Egypt
\end{abstract}

Email: orabi@ieee.org Tel.: +201001885361 Fax: +20 974661406

\begin{abstract}
An on chip integrated power management circuit with maximum power point tracking (PM-MPPT) control is proposed in this paper in order to achieve high efficiency Photovoltaic (PV) system. The proposed PM-MMPT circuit mitigates partial shading issues which exist in PV systems by utilizing cell-level distributed MPPT architecture, where each cell has its own MPPT circuit, in order for each cell to produce its own maximum power without affecting other cells or being affected by other cells. The proposed PM-MPPT circuit consists of two different parts. The first part is a high-efficiency synchronous power converter stage. The second part is an analog ripple correlation control (RCC) MPPT control circuit which provides faster and efficient MPP tracking, has less circuit complexity and low power consumption. HSPICE simulation model of the proposed PM-MPPT circuit is developed with a solar cell that has $0.5 \mathrm{~V}$ open circuit voltage and 6 A short circuit current. Simulation results show that the proposed PM-MPPT circuit rapidly tracks the MPP with a tracking efficiency larger than $99 \%$ over a wide range of irradiation levels and $92 \%$ system power conversion efficiency at a $2 \mathrm{~W}$ power level. The detailed analog design of the power stage and the RCC MPPT circuits are presented and discussed in the paper based on $0.35 \mu \mathrm{m}$ CMOS technology. In addition, the PM-MMPT IC layout is presented and discussed. To validate the proposed technique and design, a comparison between the results of the proposed circuit and other reported techniques from the literature is provided. It is shown that the proposed circuit and system are able to operate with the lowest input voltage and the highest output power compared with other reported techniques. Moreover, the proposed design has the smallest size under $2 \mathrm{~W}$ power level.
\end{abstract}

Keywords: solar energy, maximum power point tracking, on-chip MPPT, partial shading. 


\section{INTRODUCTION}

With the fast developments in solar photovoltaic (PV) technology, solar PV energy is being increasingly utilized in civil and industry applications. Since the harvested output power of a PV panel varies with temperature and solar irradiance level, it is important to ensure maximum output power from PV panels under all conditions. Maximum power point tracking (MPPT) controllers are used to ensure that PV panels are operated under their highest or close to highest efficiency level. The MPPT controllers should match the industrial trends involving high tracking efficiency, robust dynamic response and minimum number of components [1]. Some commonly used MPPT algorithms and techniques are developed and presented in the literature [2-10]. Conventional Perturb and Observe (P\&O) algorithm [3-5], Incremental Conductance (IncCond) [6-7] algorithm, open-circuit voltage $\left(\mathrm{V}_{\mathrm{oc}}\right)$ based technique, and shortcircuit $\left(\mathrm{I}_{\mathrm{sc}}\right)$ current based technique [8-10] are examples of MPPT techniques. However, alone and without modifications, these conventional MPPT techniques do not perform well and fail to track the MPP(s) under partial shading conditions. This is due to the existence of multiple output power peaks that occur when bypass diodes are used [10-11]. If bypass diodes are not used, the power which can be generated from a panel is limited by the power available from the shaded cell or the cell that has the lowest power.

The development of the conventional MPPT techniques has two different approaches to mitigate partial shading effects. The first approach is modifying the conventional MPPT techniques to properly detect the global MPP. These are such as two-stage MPPT control method [12], power curve slope technique [13], particle swarm optimization (PSO) MPPT [14], load line technique [15] and dividing rectangular techniques [16-17]. However, from the industrial point of view, this approach increases the cost of the tracking system and the tracking of the MPP is less efficient under varying conditions and over a long operating time. Furthermore, these techniques require too many sensors and the algorithm itself becomes too complex for most practical applications. On other hand, the second approach utilizes the Distributed MPPT (DMPPT) concept. It has been developed to improve the MPP tracking efficiency in PV power systems by recovering the power loss resulted from the mismatch between the different PV cells [18-20]. As illustrated in Fig. 1, the DMPPT architecture is able to reduce the partial shading effect at the PV panel level when each panel has its own MPPT controller. However, the dedicated power converters are only assigned to each PV panel in this case. If a single PV cell within a panel is partially shaded, the MPPT controller will not able to locate the maximum power point of the panel.

To maximize the performance benefits of DMMPT, a dedicated power converter with MPPT function can be assigned to each cell in a PV solar panel [21-24]. However, a challenge in this cell level DMPPT architecture is to develop a high efficiency power converter and fast MPPT control circuit with low power consumption and small footprint. 


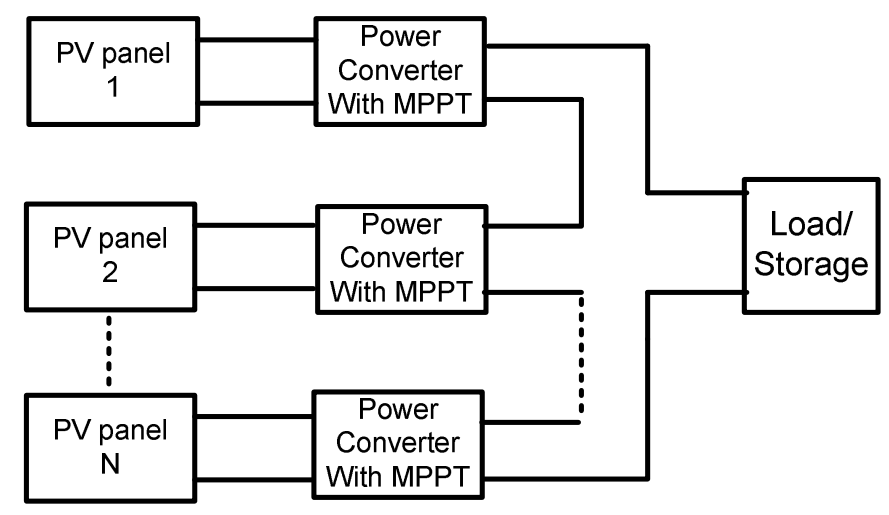

Fig. 1: Conventional DMPPT architecture of a PV system.

In this paper, an on chip integrated power management circuit with maximum power point tracking (PM-MPPT) control is proposed in order to achieve high efficiency Photovoltaic (PV) system. The proposed PM-MMPT circuit mitigates partial shading issues which exist in PV systems by utilizing cell-level distributed MPPT architecture, where each cell has its own MPPT circuit, in order for each cell to produce its own maximum power without affecting other cells or being affected by other cells. The MPPT tracking circuit is based on Ripple Correlation Control (RCC) algorithm [25] that depends on the ripple which appears on the PV cell voltage and current due to the switching of the converter. RCC is implemented using a relatively simple analog circuit with a high switching frequency in order to reduce the size and the cost of the passive components and so decrease the size of the chip and system. Also, it is designed with a high accuracy to track the MPP quickly and accurately even under varying irradiance levels and other atmospheric conditions. The system implementation and the system boundary conditions under different load currents and different irradiation levels are evaluated in order to define the stability region of the system. The operation of the system with connecting multi-cell in series is also investigated. The die layout of the proposed system is presented in this paper. Finally, a comparative study between the proposed PM-MPPT circuit and reported techniques is illustrated.

\section{PROPOSED SySTEM ILLUSTRATION}

Cell-level DMPPT architecture is realized by attaching a PM-MPPT integrated circuit to the output of each single solar cell as illustrated in Fig. 2. The dark gray square named "MPPT" includes an on-chip integrated DC-DC boost power converter and an RCC algorithm based MPPT controller, as illustrated in Fig. 3. The boost converter is used to step up the output voltage because the cell voltage is low. To create a PV panel immune to partial shading and mismatch effects, the outputs of several PM-MPPT circuit power modules are connected in series to form a sub-string of solar cells with PM-MPPT circuits or a panel system as illustrated in Fig. 4. Using the proposed architecture, the MPP will be tracked for each cell, and therefore even if one or more cells are partially shaded, they will not affect the output power of the other PM-MPPT circuits in the system. Fig. 5 illustrates the integrated synchronous boost converter, which in this work it has the following main specifications: $0.5 \mathrm{~V}$ input voltage, which is the open circuit voltage of the cell, $1.2 \mathrm{~A}$ output current and $500 \mathrm{kHz}$ switching frequency. 


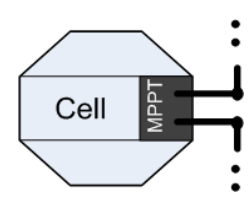

Fig. 2: The connection of a single cell to a PM-MPPT circuit.

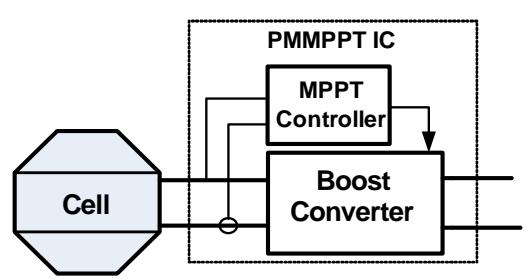

Fig. 3: Schematic illustration of a single cell connected to a PM-MPPT circuit.

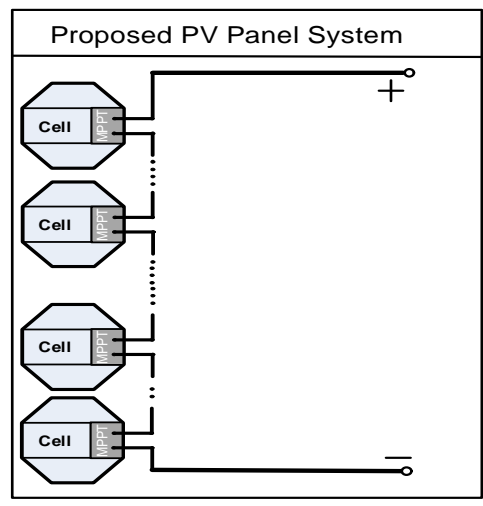

Fig. 4: Solar PV panel with the proposed PM-MPPT control ICs.

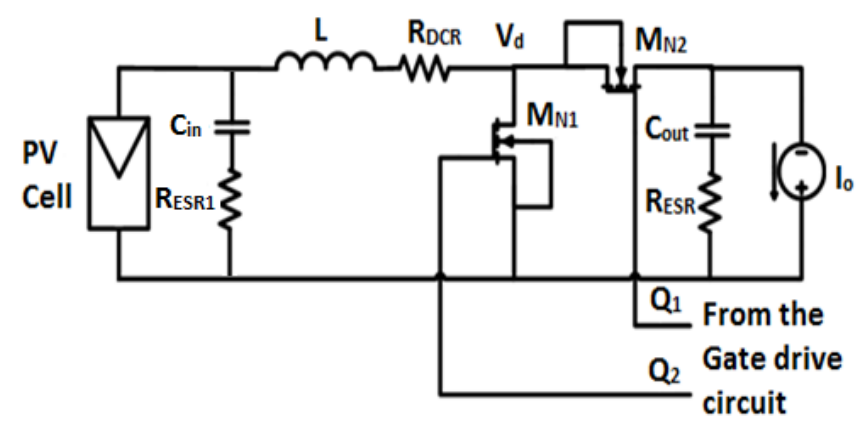

Fig. 5: The synchronous boost converter circuit.

As previously mentioned, the output power of the PV system is significantly affected by the irradiation and temperature change. The P-V curve of the solar cell is illustrated in Fig. 6. The maximum power point $\left(\mathrm{P}_{\max }\right)$ divides the $\mathrm{P}-\mathrm{V}$ curve into two regions. If the operating point is in the region 1, the voltage signal and the power signal increase simultaneously. On the other hand, if the operating point is in the region 2, the voltage signal increases while the power signal decreases. In order to obtain a maximum output power, the system should operate as close as possible to the maximum power point. A ripple correlation control algorithm RCC is used to produce a maximum power from each PV cell whatever the operating point is in a region 1 or a region 2 in conjunction with the synchronous boost converter in the proposed PM-MPPT circuit.

\section{PM-MPPT PROPOSED CIRCUIT BLOCK DIAGRAM}

The RCC MPPT depends mainly on the system ripples technique. The algorithm of the RCC is shown in Fig.7. In the RCC algorithm, the solar cell voltage and current instantaneous waveforms are continuously sensed. Since the boost converter introduces voltage and current ripples, these ripples are considered the change in the waveforms. The cell power is then obtained through multiplying both cell voltage and current instantaneous waveforms. The slope of the cell voltage ripple (dV) and the slope of the cell power ripple (dP) are recorded. If the signs of dP and $\mathrm{dV}$ are the same, the boost converter duty cycle should be increased. On the other hand, if the signs of $\mathrm{dP}$ and $\mathrm{dV}$ are opposite, the duty cycle should be decreased. By changing the duty cycle of the boost converter, the solar cell 
operating point is moved toward its maximum power point. To avoid the complexity, the RCC technique is designed using simple analog circuits. The block diagram of the MPPT control circuit is illustrated in Fig. 8. A current sensor circuit is used to sense the inductor current and produce a voltage signal $\left(\mathrm{V}_{\text {sense }}\right)$. The cell output voltage is multiplied by the voltage signal $\left(\mathrm{V}_{\text {cell }}\right)$ and a voltage signal that indicates the output power of the cell is produced.

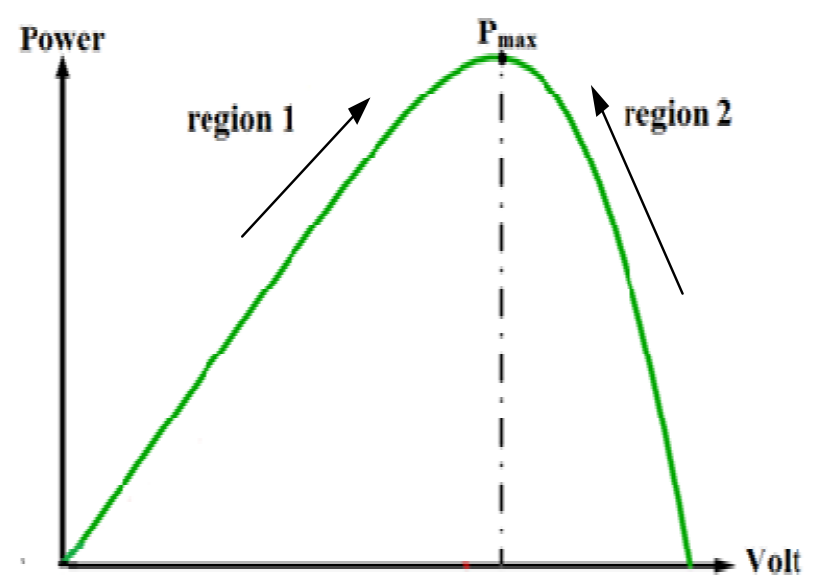

Fig. 6: P-V curve of a photovoltaic solar cell.

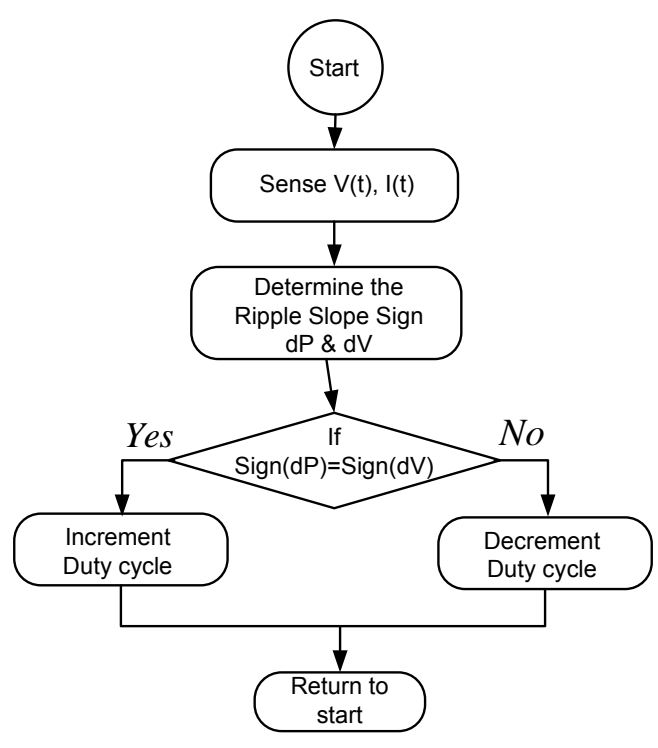

Fig.7: RCC control circuit algorithm flowchart.

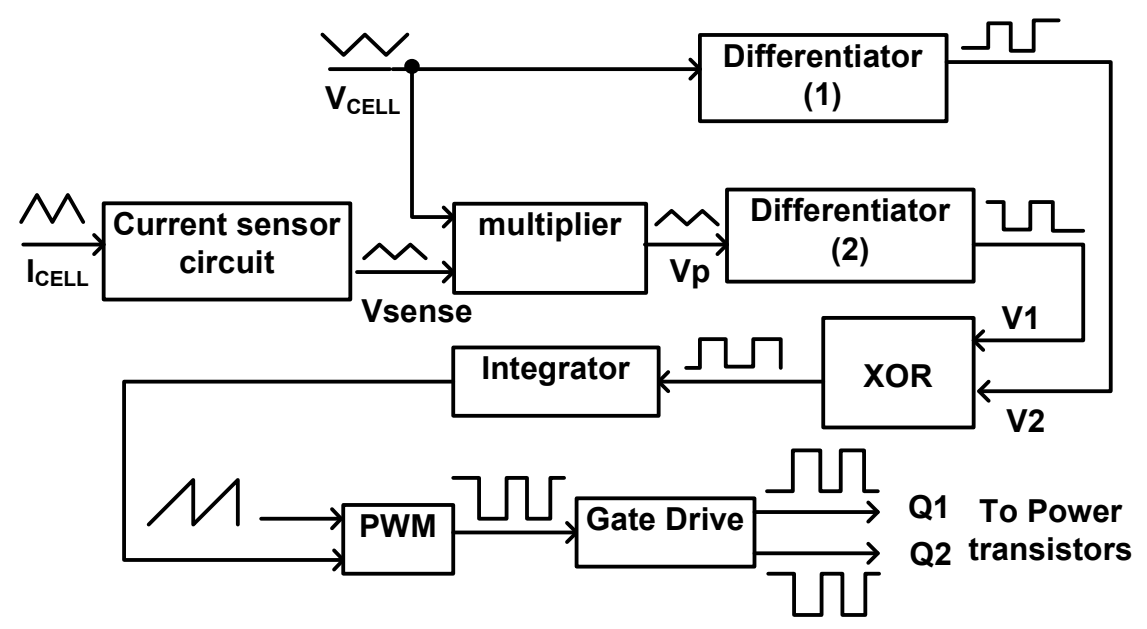

Fig. 8: Block diagram of MPPT circuit.

The multiplier output signal $\left(\mathrm{V}_{\mathrm{p}}\right)$ and the cell voltage signal $\left(\mathrm{V}_{\text {cell }}\right)$ are fed to two differentiator circuits in order to identify the location of the operating point on the P-V curve. When the system operates in region 1 (see Fig. 6), the output signals of the two differentiators $\left(\mathrm{V}_{1}\right.$ and $\left.\mathrm{V}_{2}\right)$ are in phase. The outputs of the two differentiator circuits are applied to an XOR circuit. If the output of the XOR is at logic 0 , the duty cycle of the signal that drives the power 
switches are decreased to reach the maximum power point, and vice versa. The output of the XOR circuit is fed to an integrator circuit that produces an average value of the input signal, which indicates the location of the operating point. The output signal of the XOR circuit is compared with a generated sawtooth signal in order to produce a train of pulses with a duty cycle determined by the generated DC signal. The train of pulses with a duty cycle is used to turn ON and OFF the power transistor switches (which are in this case MOSFETs) in order to control the voltagecurrent operating point of the boost power converter such that the PC solar cell is operating at its MPP.

In the case when the operating point is in region 2 (see Fig. 6), the output signals of the two differentiator circuits are out of phase. The output signal of the XOR circuit is at logic 1 . The duty cycle of the signal that drives the power switches will increase in order to get closer to the maximum power point.

The output signal of the pulse width modulation (PWM) circuit is not powerful enough to drive the power switches. Therefore, the output of the PWM is applied to a gate drive circuit that drives the power MOSFETs with dead-time control. Dead-time control prevents the two power switches from turning on at the same time in order to avoid a shoot through condition.

\section{CIRCUIT DESIGN FOR THE PM-MPPT SYSTEM}

The proposed PM-MPPT circuit consists of the boost converter circuit and the controller circuit that performs MPPT for each solar cell. It is designed using $0.35 \mu \mathrm{m}$ CMOS technology [26] and simulated using HSPICE software. The design of each block for the proposed PM-MPPT circuit is discussed next.

\section{A. Synchronous DC-DC Boost Power Converter}

The design of a highly efficient boost converter in order to maximize the overall system efficiency with the PMMPPT circuit to increase a captured power from the PV cell is very important. Because N-MOSFET has low resistance compared with P-MOSFET, the design utilizes two N-MOSFETs for lower conduction losses. The rootmean square (RMS) of the current in the $\operatorname{MOSFET~}_{\mathrm{N} 1}$ and synchronous MOSFET $\mathrm{M}_{\mathrm{N} 2}$ is equal to [27]:

$$
\mathrm{I}_{\mathrm{RMS}}\left(\mathrm{M}_{\mathrm{N} 1}\right)=\mathrm{I}_{\mathrm{L}_{\mathrm{RMS}}} \times \mathrm{D}, \quad \mathrm{I}_{\mathrm{RMS}}\left(\mathrm{M}_{\mathrm{N} 2}\right)=\mathrm{I}_{\mathrm{L}_{\mathrm{RMS}}} \times(1-\mathrm{D})
$$

where $\mathrm{I}_{\mathrm{L}_{\mathrm{RMS}}}$ is the RMS current of the boost inductor and $\mathrm{D}=$ Ton/Tsw is the duty cycle, Ton is the time duration when MN1 is turned $\mathrm{ON}$ and Tsw $=1 / \mathrm{Fsw}$ is the duration of the switching cycle. When the duty cycle is large, the RMS current of the MOSFET $M_{N 1}$ is higher than that of the synchronous MOSFET $M_{N 2}$. For high efficiency, the internal resistance of the main MOSFET MN1 $\left(\mathrm{R}_{\mathrm{on} 1}\right)$ should be designed lower than internal resistance of the synchronous MOSFET MN2 $\left(\mathrm{R}_{\mathrm{on} 2}\right)$.

For a stable operation of the RCC controller, an inductor ripple $\Delta \mathrm{i}$ of about $15 \%$ is selected and the inductor value is calculated using the following equation:

$$
\mathrm{L}=\frac{\mathrm{V}_{\mathrm{PV}} * \mathrm{D}}{2 * \Delta \mathrm{i} * \mathrm{~F}_{\mathrm{Sw}}}
$$


where, $\mathrm{V}_{\mathrm{PV}}$ is the $\mathrm{PV}$ voltage and $\mathrm{F}_{\mathrm{Sw}}$ is the switching frequency. The value of the switching frequency is selected to be $500 \mathrm{kHz}$ to keep lower inductor value. Using (2), an inductor of $400 \mathrm{nH}$ with a DC resistance of 1.5 $\mathrm{m} \Omega$ is selected.

The output voltage ripple is an important design factor in the PV system to ensure smooth output voltage for the load especially when the load is a grid-connected inverter. As the selected operating switching frequency is high, the required output capacitor value is small. The required output capacitor value can be calculated using the following equation [28]:

$$
\mathrm{C}_{\text {out }}=\frac{\mathrm{V}_{\mathrm{o}} \times \mathrm{D}}{2 \times \mathrm{R}_{\mathrm{o}} \times \Delta \mathrm{V}_{\mathrm{o}} \times \mathrm{F}_{\mathrm{sw}}}
$$

where, $V_{o}$ and $\Delta V_{o}$ are the output voltage and the output voltage ripple, respectively. $R_{o}$ is the resistance that represents the load. Using (3), a capacitor of $50 \mu \mathrm{F}$ with ESR of $2 \mathrm{~m} \Omega$ is selected.

In addition, low input capacitor value is selected based on the required input voltage ripple for the RCC control. The input voltage ripple is multiplied with the voltage signal from the current sensor to obtain power, as illustrated in Fig. 8. The value of the input voltage ripple defines the possible window of the operating range of the multiplier circuit. The input voltage ripple is a function of irradiation. Therefore, an input capacitor is required to bind the voltage ripple within a desired window. It is worth noting that the input voltage ripple is an important design factor for the RCC control to ensure high tacking efficiency for the MPP especially with low irradiation conditions. Fig. 9 shows a plot for the input voltage ripple as a function of the value of the input capacitor under different irradiation values (IRR). The input voltage ripple increases at low irradiation conditions and so the design should limit this value. Higher voltage ripples cause the multiplier to be saturated and therefore it becomes unable to detect the power variations. This is considered as undesired operation as it affects the system performance and overall stability of the RCC controller. As can be concluded from Fig. 9, an input capacitor with a value of $1 \mu \mathrm{F}$ makes the system stable over a wide irradiation range from 300 to $1000 \mathrm{~W} / \mathrm{m}^{2}$ for the design in this work.

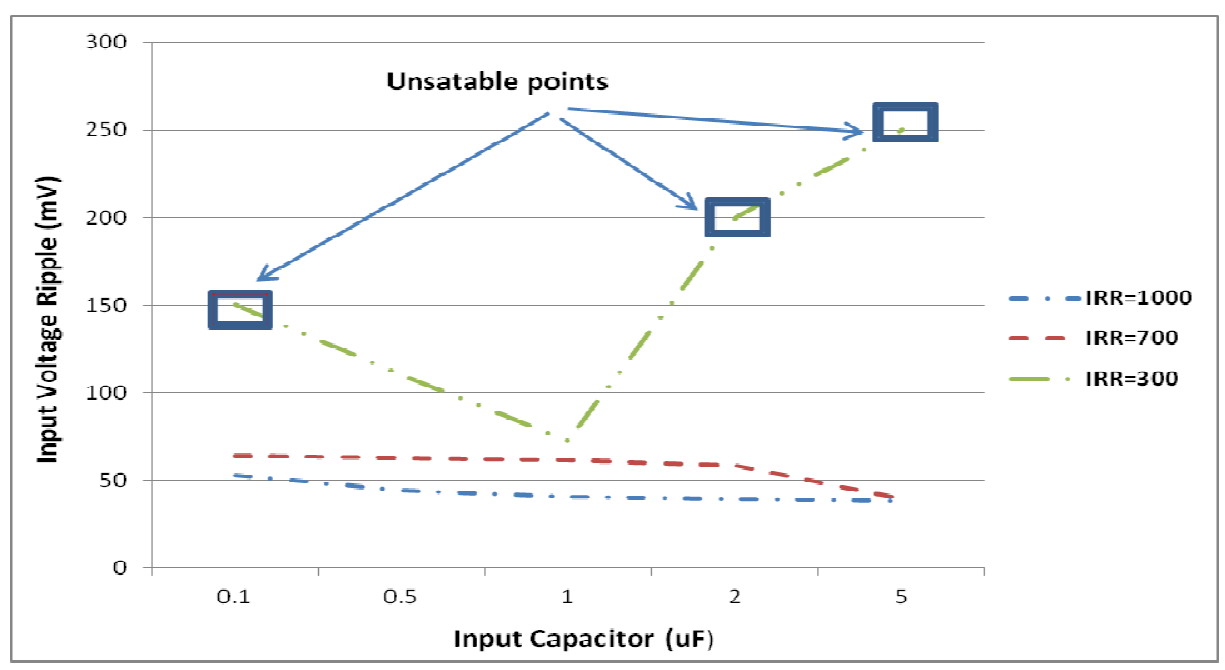

Fig. 9: Input voltage ripple as a function of input capacitor value for the design of this work. 
The overall converter efficiency at desired operating points can be optimized by reducing the converter power losses/consumption at these operating points. The power loss of a converter is a combination of the conduction losses caused by the resistive parasitic impedances and the switching losses due to the capacitive parasitic impedances of the circuit components [29].

The conduction loss can be approximated by:

$$
\mathrm{P}_{\text {cond }}=\mathrm{i}_{\mathrm{L}_{\mathrm{RMS}}}^{2} \times \mathrm{D} \times \mathrm{R}_{\mathrm{on} 1}+\mathrm{i}_{\mathrm{L}_{\mathrm{RMS}}}^{2} \times(1-\mathrm{D}) \times \mathrm{R}_{\mathrm{on} 2}+\mathrm{i}_{\mathrm{L}_{\mathrm{RMS}}}^{2} \times \mathrm{R}_{\mathrm{DCR}}
$$

where, $R_{D C R}$ is the $\mathrm{DC}$ resistance of the boost inductor.

The switching losses mainly depend on the parasitic capacitances, the current, voltage and the switching frequency. The switching loss can be approximated by [29]:

$$
\mathrm{P}_{\mathrm{sw}}=\frac{1}{2} \times \mathrm{V} * \mathrm{~F}_{\mathrm{sw}} \times\left[\mathrm{i}_{\mathrm{L}_{\text {Valley }}} \times \mathrm{t}_{\mathrm{rise}}+\mathrm{i}_{\mathrm{L}_{\mathrm{Pk}}} \times \mathrm{t}_{\mathrm{fall}}\right]
$$

where $V$ is the voltage changed during switch transition that equals the drain voltage $V_{d}$ for MOSFET $M_{N 1}$ and equals $\mathrm{V}_{\mathrm{d}}-\mathrm{V}_{\mathrm{o}}$ for MOSFET $\mathrm{M}_{\mathrm{N} 2}$ (Fig. 5). $\mathrm{i}_{\mathrm{L}_{\mathrm{Pk}}}=\mathrm{I}_{\mathrm{L}}+\Delta \mathrm{i}_{\mathrm{L}}, \mathrm{i}_{\mathrm{L}_{\mathrm{Valley}}}=\mathrm{I}_{\mathrm{L}}-\Delta \mathrm{i}_{\mathrm{L}}$ are the valley and the peak of the inductor current, respectively. $t_{\text {rise }}$ and $t_{\text {fall }}$ are the rise and fall time intervals required from switching on/off.

It is reported in [28] that a high efficiency can be achieved when the conduction loss is equal to the sum of the switching and gate drive losses. This is achieved by changing the number of the paralleled MOSFETs for the main switch $\mathrm{M}_{\mathrm{N} 1}$ and the number of the paralleled MOSFETs for the synchronous switch $\mathrm{M}_{\mathrm{N} 2}$ in order to vary the switching loss and conduction loss and optimize the overall efficiency of the MPPT circuit and system. Table 1 illustrates different selected cases for the number of paralleled power MOSFETs operating at $0.5 \mathrm{MHz}$ switching frequency. It can be observed that for this paper design case 5 gives the highest converter efficiency versus size as shown in Fig. 10.

Table 1: Number of paralleled power MOSFETs selected options for Fig. 10 plot

\begin{tabular}{|c|c|c|c|c|c|c|c|}
\hline Case study & 1 & 2 & 3 & 4 & 5 & 6 & 7 \\
\hline $\mathrm{M}\left(\mathrm{M}_{\mathrm{N} 1}\right)$ & 45000 & 45000 & 45000 & 45000 & 45000 & 45000 & 45000 \\
\hline $\mathrm{M}\left(\mathrm{M}_{\mathrm{N} 2}\right)$ & 72000 & 57600 & 43200 & 36000 & 32400 & 21600 & 14000 \\
\hline
\end{tabular}




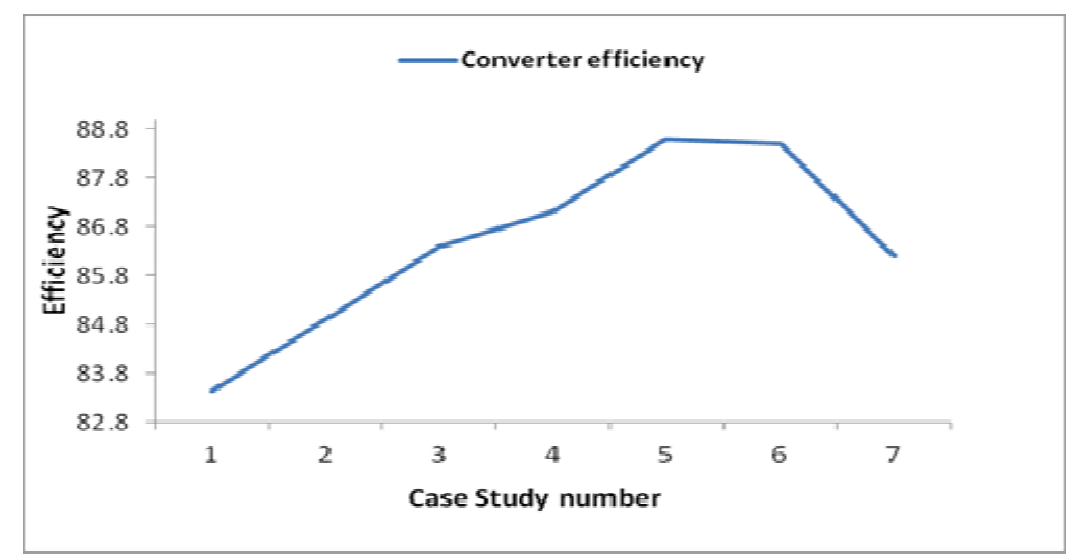

Fig. 10: Converter efficiency for different number of paralleled MOSFETs as shown in Table 1 at full irradiation.

\section{B. Current Sensor Circuit}

Fig. 11 shows the schematic circuit diagram for the current sensor. The gates of the main power MOSFETs $\mathrm{M}_{\mathrm{N} 2}$ and the sense MOSFET $\mathrm{M}_{\mathrm{N} 3}$ are connected together. During the on time of $\mathrm{M}_{\mathrm{N} 2}$, the inductor current passes through the power MOSFET $M_{N 2}$. The current passes through the transistors $M_{N 3}$ and $M_{N 4}$, which are part of the current sensing circuit, represents the sensed positive slew rate part of the inductor current. $\mathrm{M}_{\mathrm{N} 3}$ and $\mathrm{M}_{\mathrm{N} 4}$ are used to mirror this part of the instantaneous inductor current with suitable gain that is defined by the number of FETs used for $\mathrm{M}_{\mathrm{N} 3}$. A gate connected transistors $\mathrm{M}_{\mathrm{N} 5}$ and $\mathrm{M}_{\mathrm{N} 7}$ form a voltage follower that forces the drain voltages of transistors $M_{N 4}$ and $M_{N 5}$ to be equal. $V_{d s}$ of the $M_{N 4}$ is the same as that of $M_{N 5}$. Therefore, the drain current of $M_{N 4}$ is equal to the drain current of $\mathrm{M}_{\mathrm{N} 5}$. The capacitor $\mathrm{C} 1$ is charging and the voltage on the capacitor is mirrored to the output of the sensor $\left(\mathrm{V}_{\text {sense }}\right)$ through transistors $\mathrm{M}_{\mathrm{P} 3}$ and $\mathrm{M}_{\mathrm{P} 4}$. During the off time of $\mathrm{M}_{\mathrm{N} 2}, \mathrm{M}_{\mathrm{N} 3}$ is turned off. The drain current of $\mathrm{M}_{\mathrm{N} 4}$ is determined by the current $\mathrm{I}_{\mathrm{Bias}}$, and the capacitor $\mathrm{C} 1$ is discharging through the internal resistor of $\mathrm{M}_{\mathrm{N} 4}$. The signal generated through the capacitor represents the negative slew rate part of the instantaneous inductor current with the same gain of the first part [30].

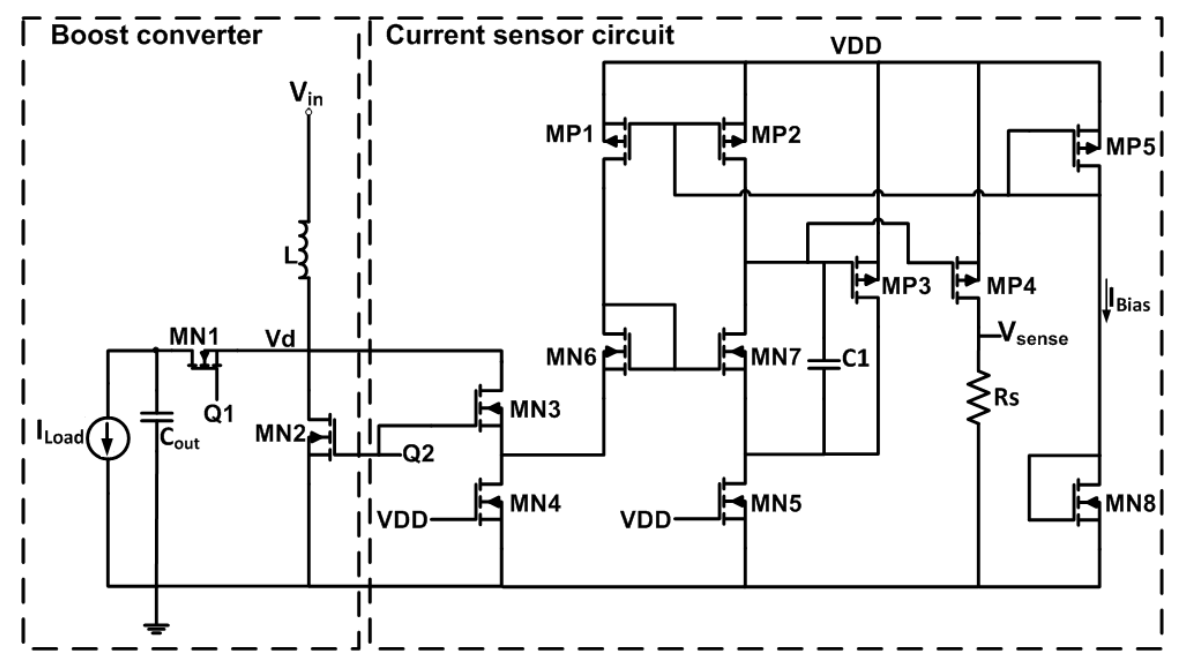

Fig. 11: The current sensor circuit diagram. 


\section{Multiplier Circuit}

Fig. 12 shows the schematic circuit diagram of the multiplier. It is used to multiply the signal of the cell output voltage and the signal from the output of the current sensor circuit to produce a power signal of the cell. A wide range analog multiplier [31] is used to achieve the wide input dynamic range voltage. The multiplier design is based on a quarter square algebraic identity technique. It consists of two active attenuator circuits MP6-MP9, two shunt feedback buffer circuits MP10-MP17 and MN13-MN16. The active attenuator circuits and two shunt feedback buffer circuits are applied to bias the differential squaring circuit MN9-MN12.The multiplier output can be expressed as [31]:

$$
\mathrm{V}_{\mathrm{o}} \alpha\left(\mathrm{I}_{\mathrm{D} 12}+\mathrm{I}_{\mathrm{D} 10}\right)-\left(\mathrm{I}_{\mathrm{D} 9}+\mathrm{I}_{\mathrm{D} 11}\right) \alpha \frac{\mu \mathrm{C}_{\mathrm{ox}}}{8}\left(\frac{\mathrm{W}}{\mathrm{L}}\right) \mathrm{V}_{\mathrm{X}} \mathrm{V}_{\mathrm{Y}}
$$

where $\mathrm{V}_{\mathrm{X}}$, and $\mathrm{V}_{\mathrm{Y}}$ are the input signals, and $\mathrm{I}_{\mathrm{D} 9}, \mathrm{I}_{\mathrm{D} 10}, \mathrm{I}_{\mathrm{D} 11}, \mathrm{I}_{\mathrm{D} 12}$ are the drain currents of transistors $\mathrm{M}_{\mathrm{N} 9}, \mathrm{M}_{\mathrm{N} 10}$, $\mathrm{M}_{\mathrm{N} 11}$ and $\mathrm{M}_{\mathrm{N} 12}$, respectively. The achieved dynamic input range is from $0 \mathrm{~V}$ to $3 \mathrm{~V}$ which grantees that the circuit will operate properly in whole input ranges, from 0 to the cell voltage $0.5 \mathrm{~V}$ and from 0 to the output of the current sensor circuit $2 \mathrm{~V}$.

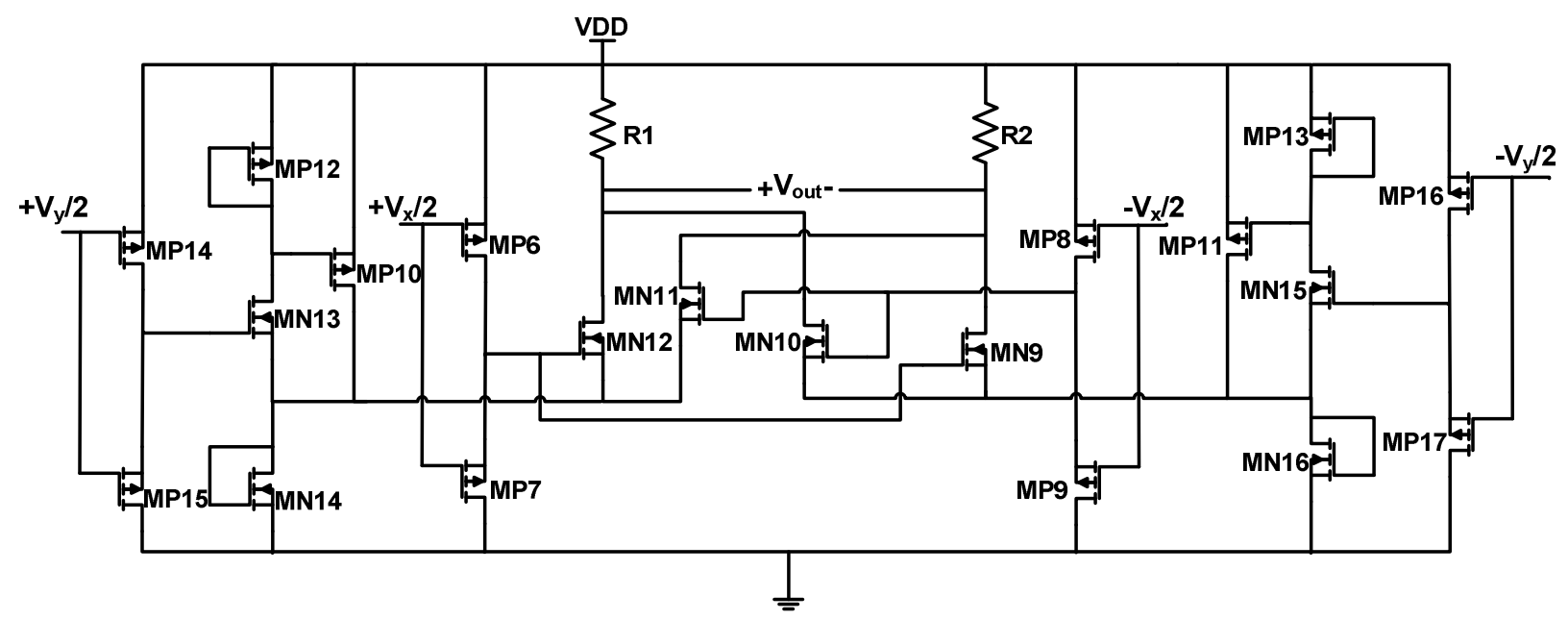

Fig.12: The multiplier circuit diagram.

\section{Differentiator Circuit}

The circuit diagram of the differentiator is shown in Fig. 13. The differentiator differentiates its input signal to indicate whether the input signal is increasing or decreasing. Fig. 14 shows the schematic circuit diagram of CMOS operational amplifier that operates as a differentiator. The input signal range is not determined, so an internal bias circuit, which is a voltage divider circuit $\mathrm{R}_{4}-\mathrm{R}_{7}$, is used to ensure that the operation of the differentiator is not dependent on the value of the input signal. A capacitor $\mathrm{C}_{3}$ is used at the input to block the DC component of the input signal. There are two differentiators in the controller circuit, as illustrated in Fig. 8. The first one is used to differentiate the cell voltage signal. The second differentiator is used to differentiate the output signal of the multiplier circuit that indicates the cell power. When the slope of the input signal is negative, the output signal of the 
differentiator is at logic 0 . On the other hand, when the slope of the input signal is positive; the output signal of the differentiator is at logic 1 .

\section{E. XOR Circuit}

The two output signals of the two differentiator circuits are fed to an XOR circuit. When the XOR output signal is at logic 0 , the power signal and the voltage signal are in-phase. On the other hand, when the XOR output signal is at $\operatorname{logic} 1$, the voltage signal and the power signal are out-of-phase. In this way, the operating region of the PV cell as shown in Fig. 6 can be determined.

\section{F. Integrator Circuit}

The integrator circuit is used in order to obtain the average voltage of the XOR output signal that represents the desired duty cycle of the synchronous boost converter. The output of the integrator is fed to the PWM generator in order to generate the control signal of the switches. A simple low pass filter circuit, as illustrated in Fig. 15, is used to perform the integration function.

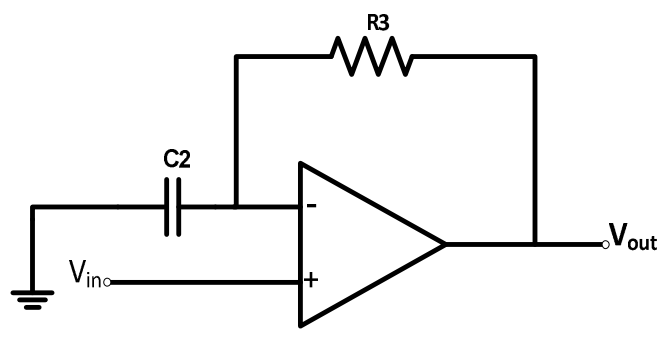

Fig. 13: The differentiator circuit.

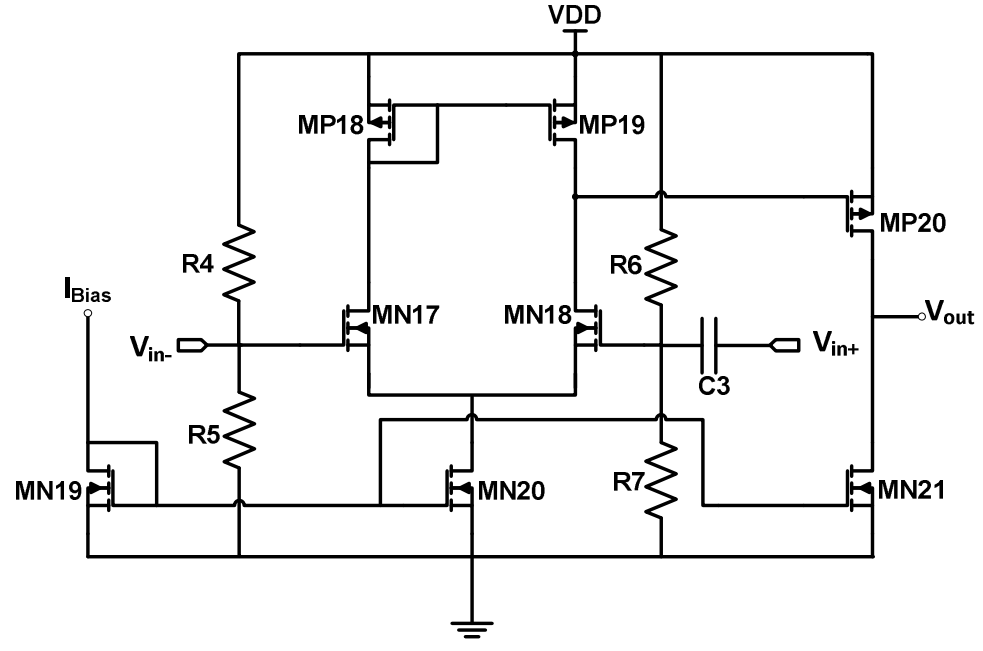

Fig.14: The schematic circuit diagram of the operational amplifier used as a differentiator.

The integrator circuit consists of $1 \mathrm{M} \Omega$ resistor and $70 \mathrm{pF}$ capacitor. A tradeoff between the convergence time and the RCC stability is required to optimize the integrator gain. In addition, the bandwidth of the integrator defines the response of the RCC. The MPP changes very slowly under varying environmental conditions compared with the high speed operation of the integrator. Therefore, the bandwidth of the integrator should be small enough to eliminate the switching harmonics and at the same time it should be high enough to improve the converter dynamics under any environmental condition changes. The bandwidth can be calculated as:

$$
\mathrm{BW}=\frac{1}{\mathrm{R} \cdot \mathrm{C}}
$$


The input to the integrator is the logic output of the XOR circuit. If the XOR circuit output signal is at logic 1 , the integrator circuit output increases and the duty cycle increases, and vice versa. The duty cycle rate of change depends on the gain of the integrator circuit.

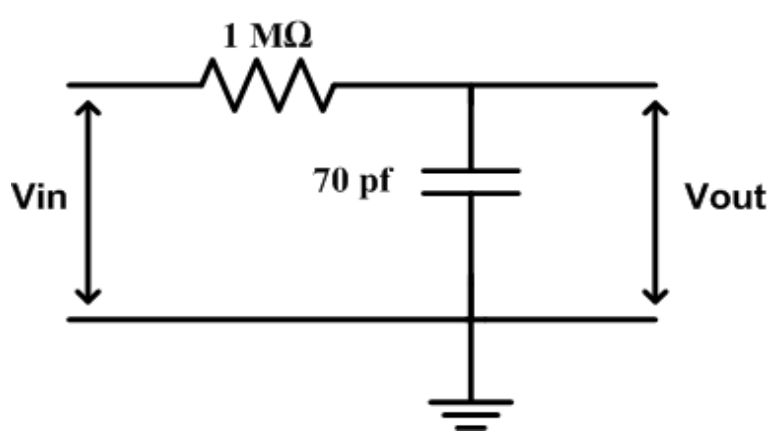

Fig. 15: The integrator circuit.

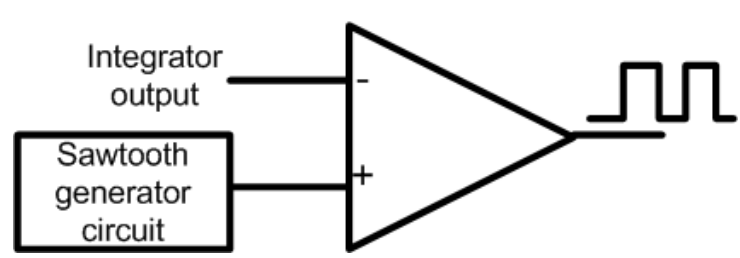

Fig. 16: The PWM circuit.

\section{G. Pulse Width Modulator (PWM)}

The pulse width modulator circuit consists of a sawtooth generator and a comparator as shown in Fig. 16. The DC voltage, which is the integrator output voltage, is compared with the generated sawtooth signal. The integrator output has a large swing voltage from $0 \mathrm{~V}$ to $2.8 \mathrm{~V}$, so a comparator with one diff-amp stage will not operate properly in the whole voltage range. Fig. 17 shows the comparator circuit used to generate train pulses with a duty cycle determined by the level of the applied DC voltage. The comparator circuit uses two complementary diff-amp stages in parallel MP21-MP22 and MN22-MN23, which allow increasing the input swing.

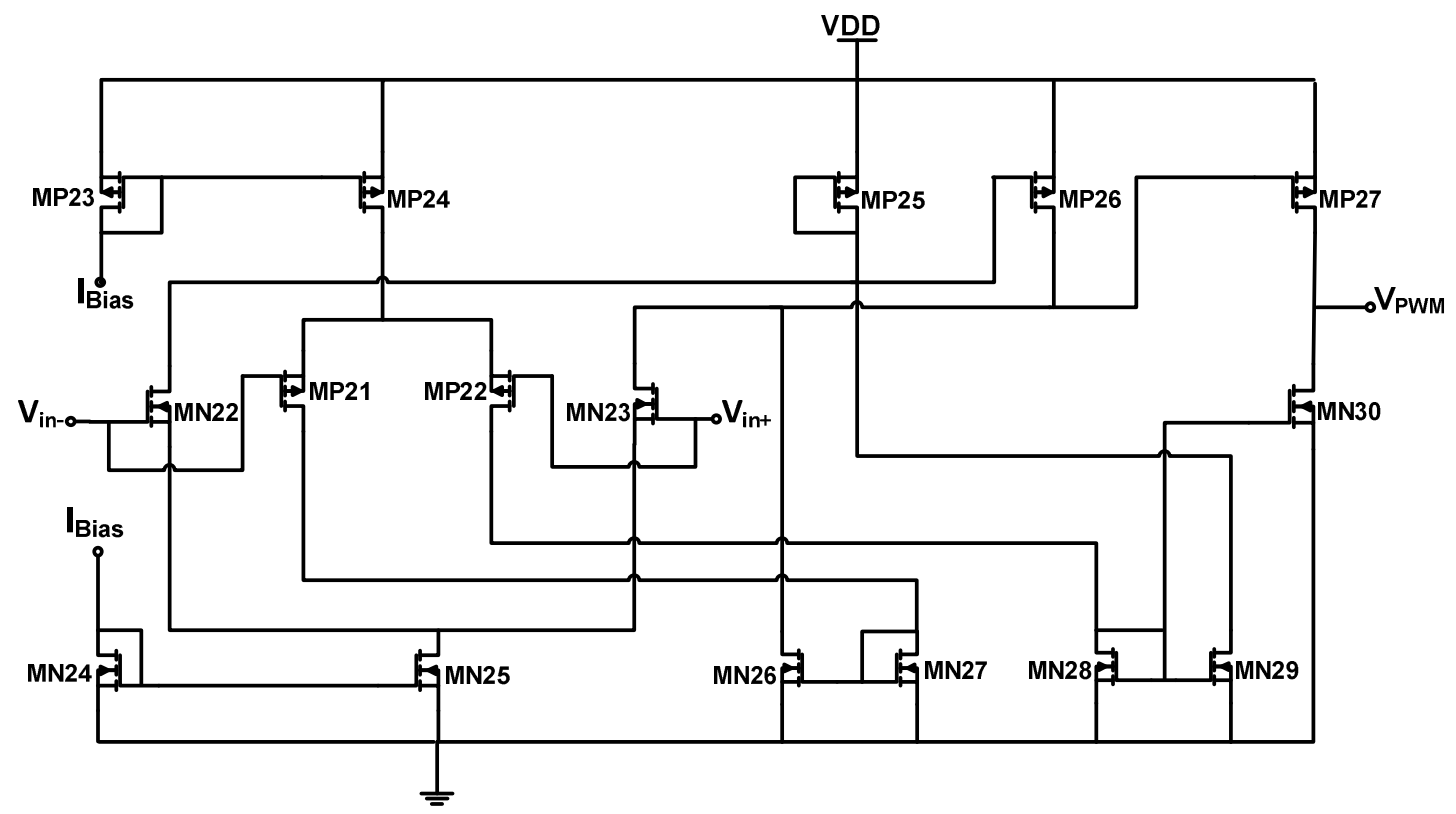

Fig. 17: The comparator circuit diagram used in the PWM circuit. 


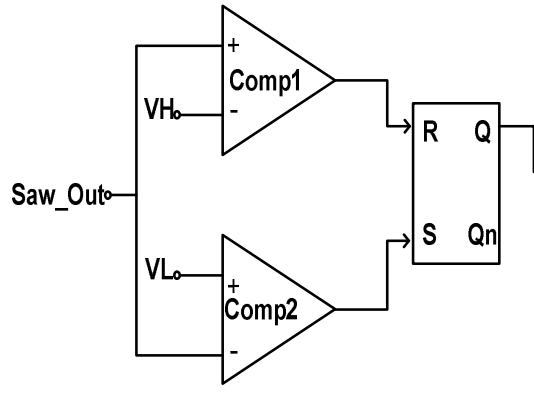

Fig. 18: The sawtooth generator circuit.

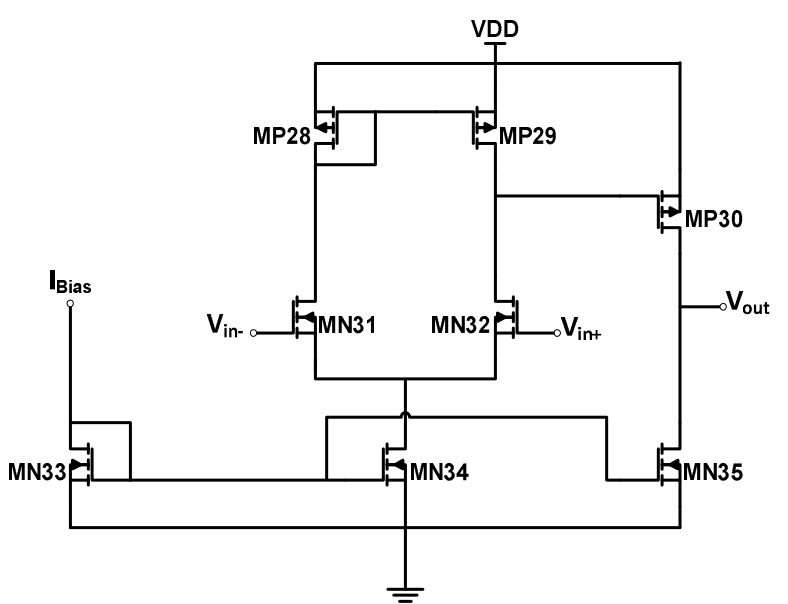

Fig. 19: The comparator circuit (Comp1) used in the sawtooth generator circuit.

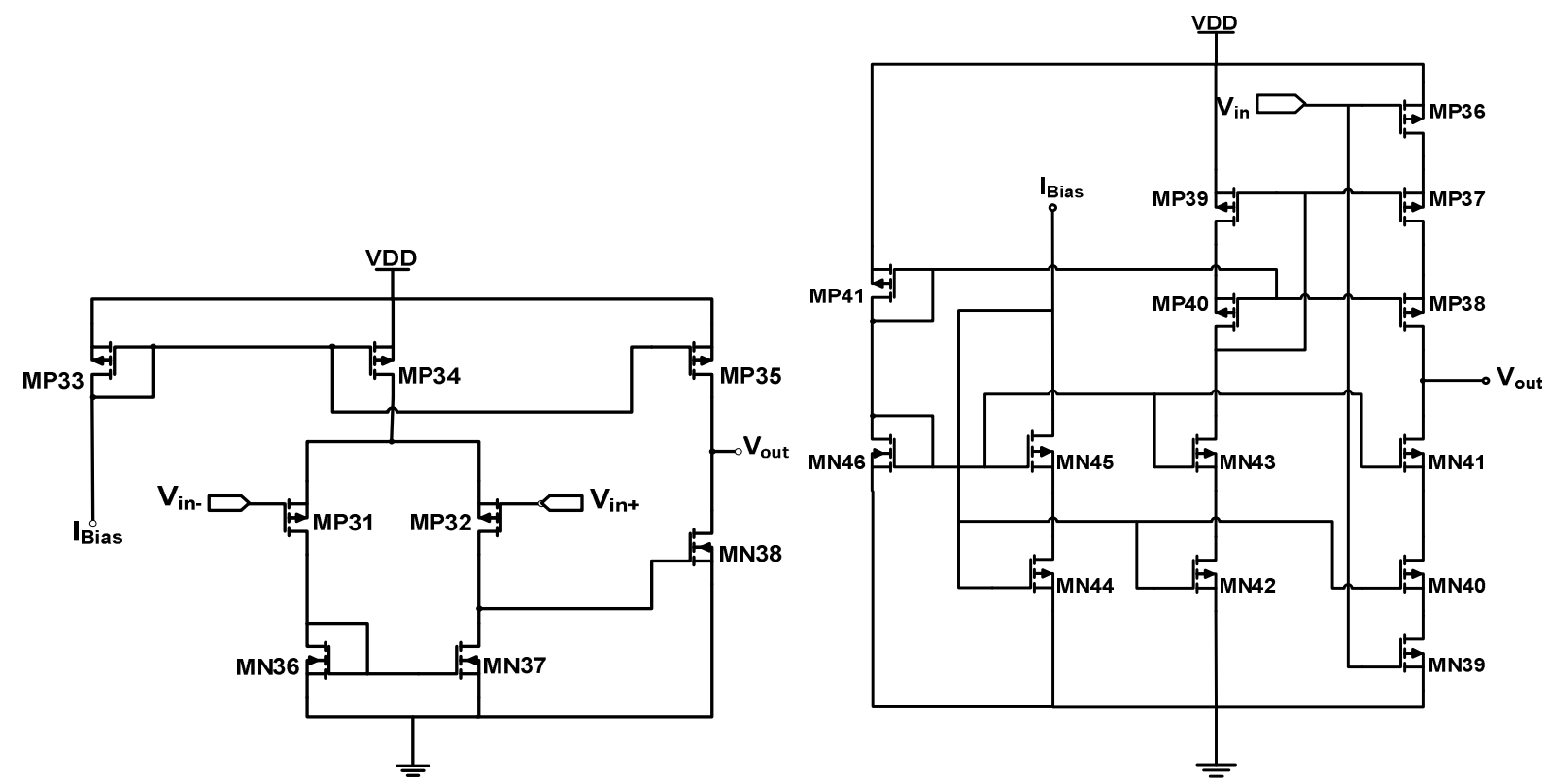

Fig. 20: The comparator circuit (Comp2) used in the sawtooth generator circuit.

Fig. 21: The current mode circuit.

The sawtooth generator circuit consists of two comparators, one RS latch, and wide range current mode circuit (CM) as shown in Fig. 18. The circuit diagram of the Comp1 is shown in Fig. 19. The schematic circuit diagram of Comp 2 is shown in Fig. 20. The reason for using different comparators is that the input signals of the Comp 1 are high so the input stage of the comparator is designed using NMOS differential amplifier. On the other hand, the input signals of the Comp 2 are low so the input stage of the comparator is designed using PMOS differential amplifier.

The current mode circuit, as illustrated in Fig. 21, converts the input voltage signal into current signal to charge the capacitor. The capacitor is charged with a constant current, $\mathrm{I}_{\mathrm{ch}}$, until an upper voltage limit is reached, and discharges with a discharge current, $\mathrm{I}_{\mathrm{Dch}}$, until a lower limit is reached. The output signal limits are set with two 
comparators. The output signals of the two comparators should toggle when the output signal exceeds the upper and the lower voltage limits VH and VL. A quick discharge to ground via a finite delay comparator causes the lower limit of the sawtooth signal to reset below $\mathrm{VL}$ and introduces a voltage error $\mathrm{V}_{\text {Error }}$. The period of the sawooth signal, $\mathrm{T}=\mathrm{Tsw}=1 / \mathrm{Fsw}$, can be calculated from the following equation:

$$
T=C \cdot\left[V_{H}-\left(V_{L}-V_{E r r o r}\right)\right] \cdot\left(\frac{1}{I_{c h}}+\frac{1}{I_{D c h}}\right)
$$

\section{H. Gate Drive Circuit}

The output of the PWM is applied to a gate drive circuit, which produces signals that drive the power transistors and to ensure the power transistors will not be turned on at the same time. The gate drive circuit, as shown in Fig. 22, consists of a NOR gate, an AND gate, two buffers, and a bootstrap circuit. The output signal of the gate drive circuit is used to drive power MOSFETs $\mathrm{M}_{\mathrm{N} 1}$ and $\mathrm{M}_{\mathrm{N} 2}$ in the boost converter circuit shown in Fig. 5. The source terminal of the transistor $\mathrm{M}_{\mathrm{N} 2}$ is not connected to ground, and therefore it requires a gate voltage signal higher than $\mathrm{V}_{\mathrm{DD}}$ to operate in the deep saturation region. The gates of transistors $\mathrm{M}_{\mathrm{N} 47}$ and $\mathrm{M}_{\mathrm{P} 42}$ are connected together. When the gate voltage of transistor $\mathrm{M}_{\mathrm{N} 47}$ is at logic 1, transistor $\mathrm{M}_{\mathrm{N} 47}$ is turned on, and transistors $\mathrm{M}_{\mathrm{P} 42}$ and $\mathrm{M}_{\mathrm{N} 1}$ are turned off. The capacitor $\mathrm{C}_{\mathrm{Boot}}$ voltage charges to $\mathrm{V}_{\mathrm{DD}}$ and the output voltage at $\mathrm{Q} 1$ is at logic 0 . When the gate voltage of transistor $\mathrm{M}_{\mathrm{N} 47}$ is at logic 0 , transistor $\mathrm{M}_{\mathrm{N} 47}$ is turned off, and transistors $\mathrm{M}_{\mathrm{P} 42}$ and $\mathrm{M}_{\mathrm{N} 2}$ are turned on. The output voltage at $\mathrm{Q} 1$ is the sum of capacitor $\mathrm{C}_{\mathrm{Boot}}$ voltage, $\mathrm{V}_{\mathrm{DD}}$, and the output voltage of the boost converter. During this time, the voltage at $\mathrm{Q} 1$ that is applied to the gate of transistor $\mathrm{M}_{\mathrm{N} 2}$ is high enough to get the transistor $\mathrm{M}_{\mathrm{N} 2}$ deeply in saturation region.

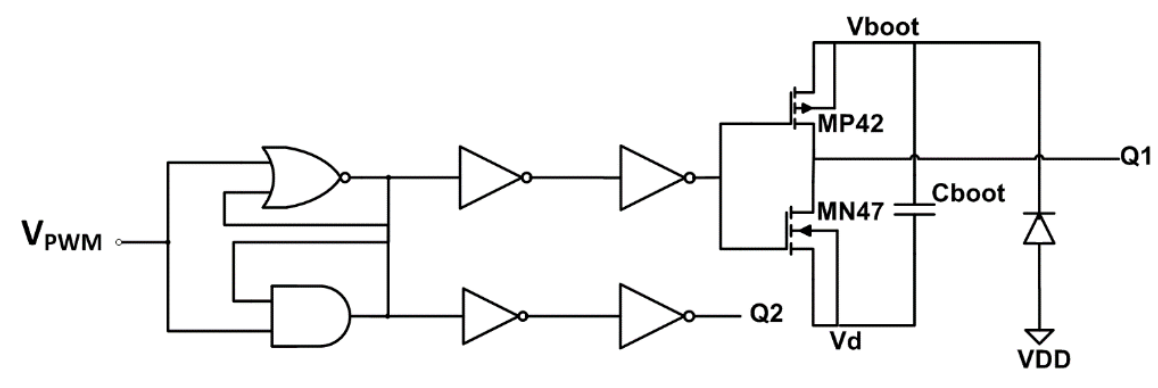

Fig. 22: The gates drive circuit.

\section{ON-CHIP INTEGRATED CIRCUIT AND SYSTEM SIMULATION RESULTS}

The proposed PM-MPPT circuit senses the PV cell voltage and current and adjusts the duty cycle of the converter circuit in order to track the maximum power point of the cell. The proposed circuit is designed using $0.35 \mu \mathrm{m}$ CMOS technology and simulated using HSPICE software. The simulation results are divided in three parts: single solar cell simulation results, full system maximum power point convergence regions and stability study, and full system cell architecture results. 


\section{A. PM-MPPT Circuit Simulation Result with Single Solar Cell}

The solar cell model used in the simulation is shown in Fig. 23. The irradiance level is controlled by changing the magnitude of current source $\left(\mathrm{I}_{\text {cell }}\right)$ in the cell model. The MPP location for a PV solar cell varies with the irradiation change. The control circuit tracks the operating point and tries to make it as close as possible to the maximum power point. The simulation results have been carried out for different values of irradiation levels. Fig. 24 illustrates the input and the output signals of the current sensor circuit. The waveform in upper graph is the solar cell current and in the lower graph is the output signal of the current sensor circuit. The power converter circuit introduces current ripples to the solar cell output current with a frequency of $500 \mathrm{kHz}$. Fig. 25 shows the variations of the cell current and the output signal of the current sensor with irradiance level changes from $1000 \mathrm{~W} / \mathrm{m}^{2}$ to 250 $\mathrm{W} / \mathrm{m}^{2}$. The current signal is increased when the irradiance level increased. The current sensor circuit operates accurately at the desired irradiation range. The inductor current changes from $6 \mathrm{~A}$ to $1 \mathrm{~A}$ and the current sensor circuit still has linear and accurate response.

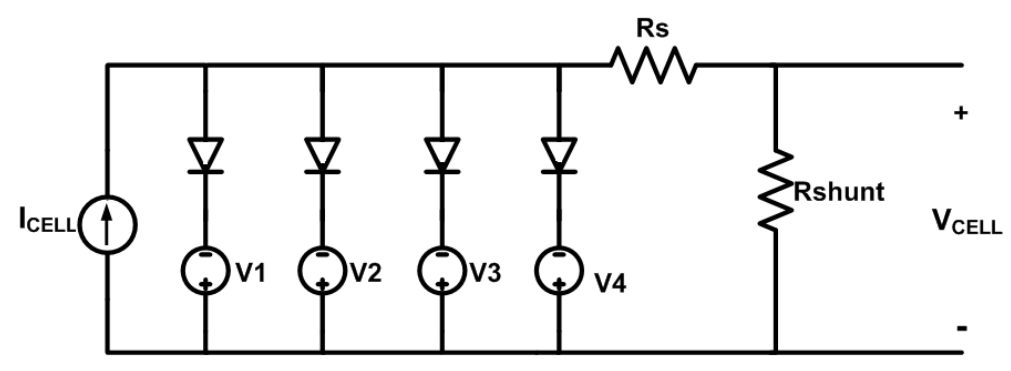

Fig. 23: The PV solar cell model.

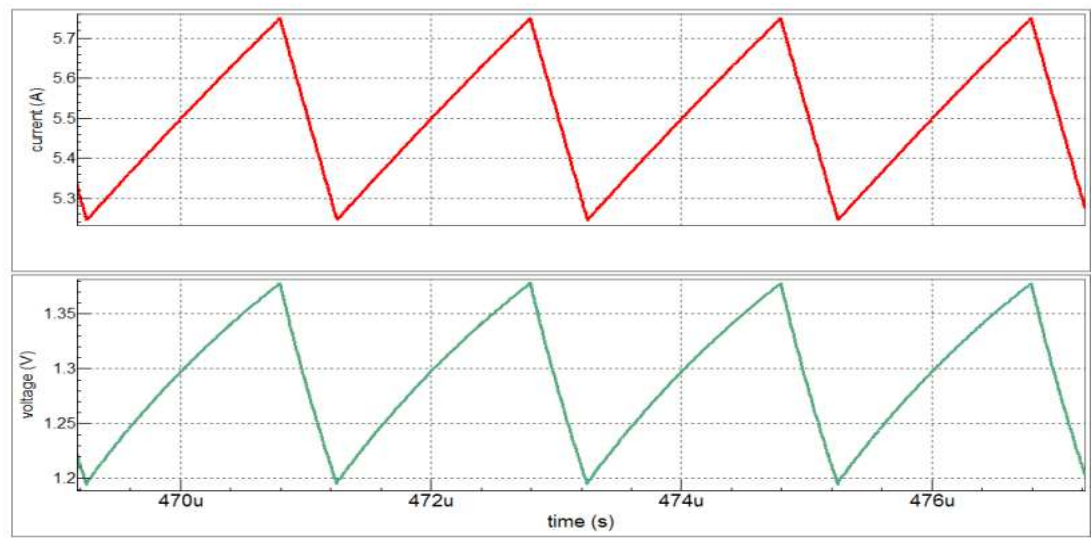

Fig. 24: Waveforms of the input and the output signals of the current sensor circuit. 


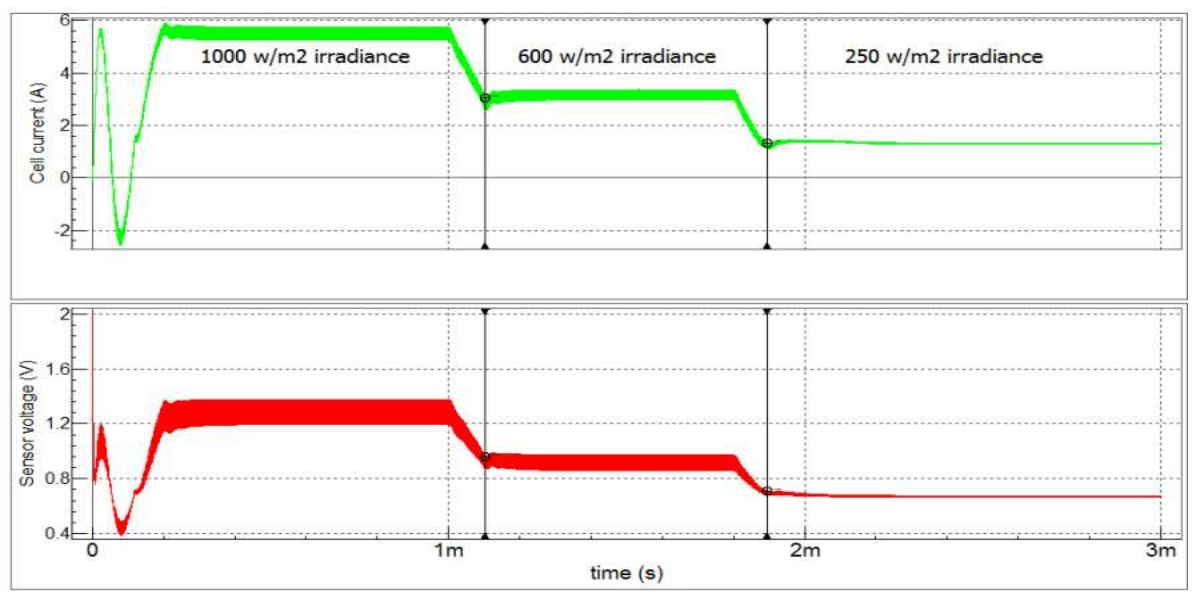

Fig. 25: Waveforms of the input and the output signals of the current sensor with irradiation change.

The input and the output of the voltage differentiator are shown in Fig. 26. The upper trace is the input signal and the lower trace is the output signal. The upper trace of Fig. 27 shows the input signal of the power differentiator circuit, which is the output signal of the multiplier circuit. The lower trace of Fig. 27 shows the output signal of the power differentiator. Fig. 26 and Fig. 27 indicate that when the slope of the differentiator input signal is positive, the output signal is at logic 1 and when the slope is negative, the output signal is at logic 0 .

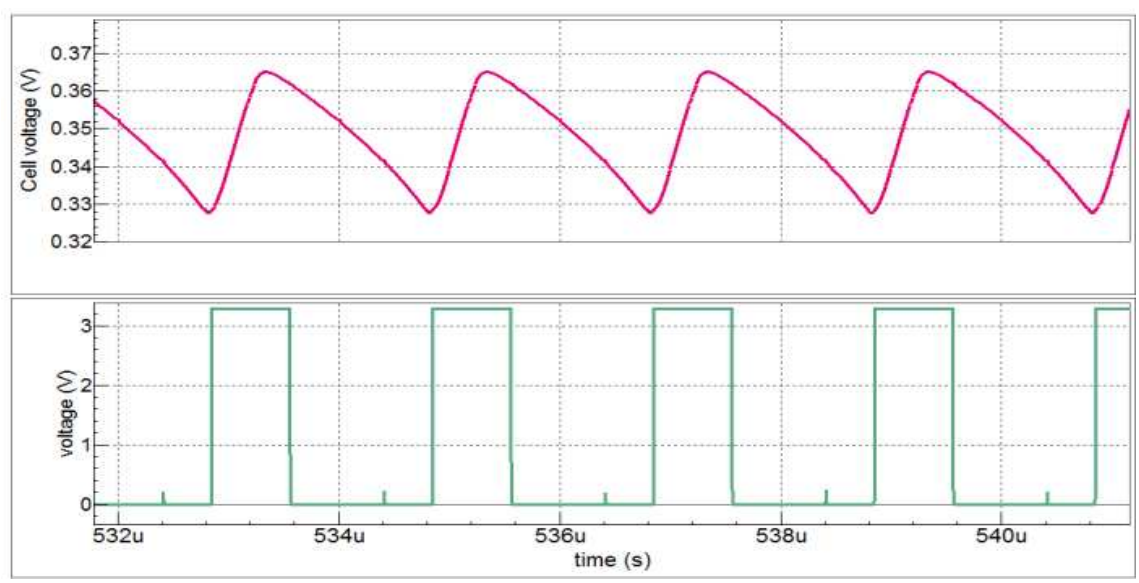

Fig. 26: The input and the output signals of the voltage differentiator. 


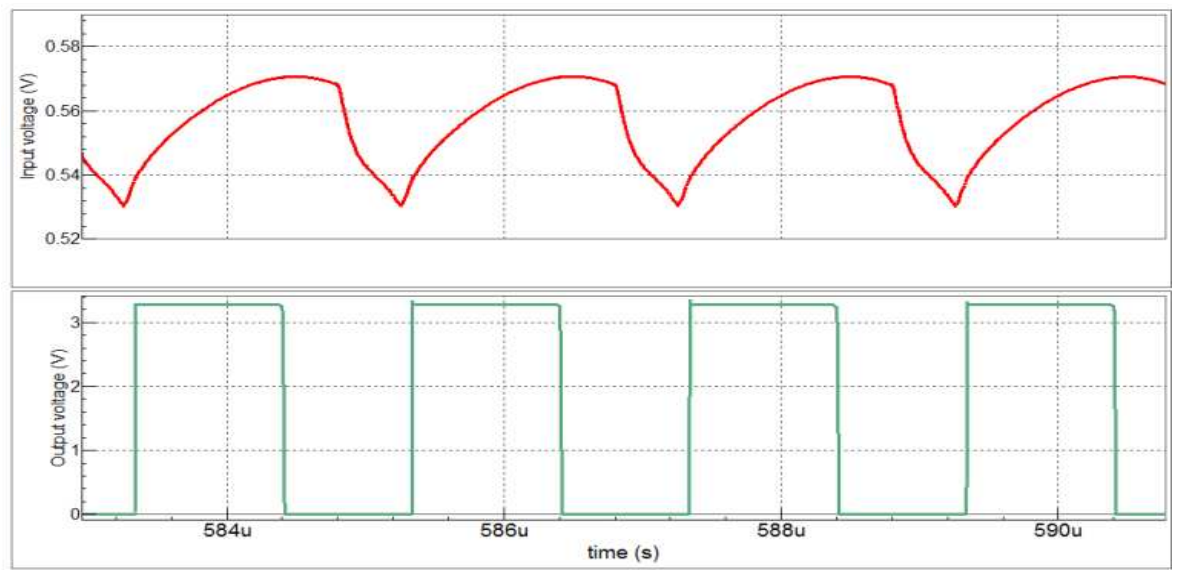

Fig. 27: The input and the output signals of the power differentiator.

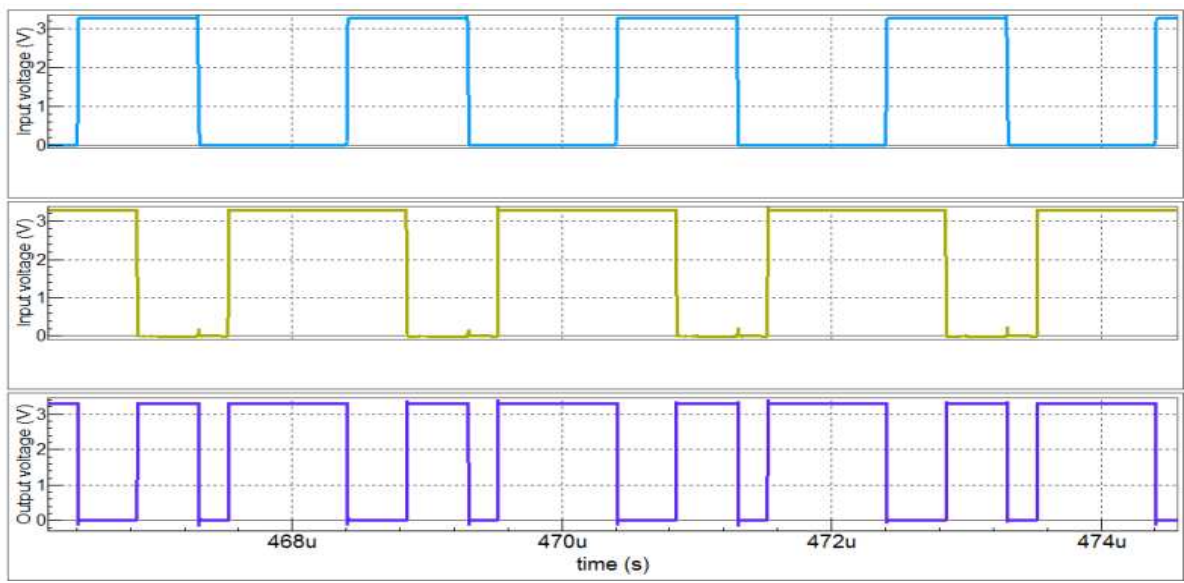

Fig. 28: The inputs and the output of the XOR circuit.

The output signals of the two differentiator circuits are fed to XOR circuit. Fig. 28 shows the input and the output signals of the XOR circuit. The upper trace is the output of the voltage differentiator signal, the middle trace is the output signal of the power differentiator circuit and the lower trace is the output signal of the XOR circuit. The upper trace of Fig. 29 shows the input signal of the integrator circuit at different irradiations (from $1000 \mathrm{~W} / \mathrm{m}^{2}$ to $250 \mathrm{~W} / \mathrm{m}^{2}$ ), which is the output signal of the XOR circuit. The lower trace is the output signal of the integrator circuit which is a DC level that is used to determine the duty cycle of the signal that drives the power transistors. The duty cycle determines the output voltage of the boost converter and the system output power. As the irradiation changes, the output voltage of the integrator circuit changes to keep the operating point location as close as possible to the maximum power point. Fig. 30 shows a zoomed in version of Fig. 29. 


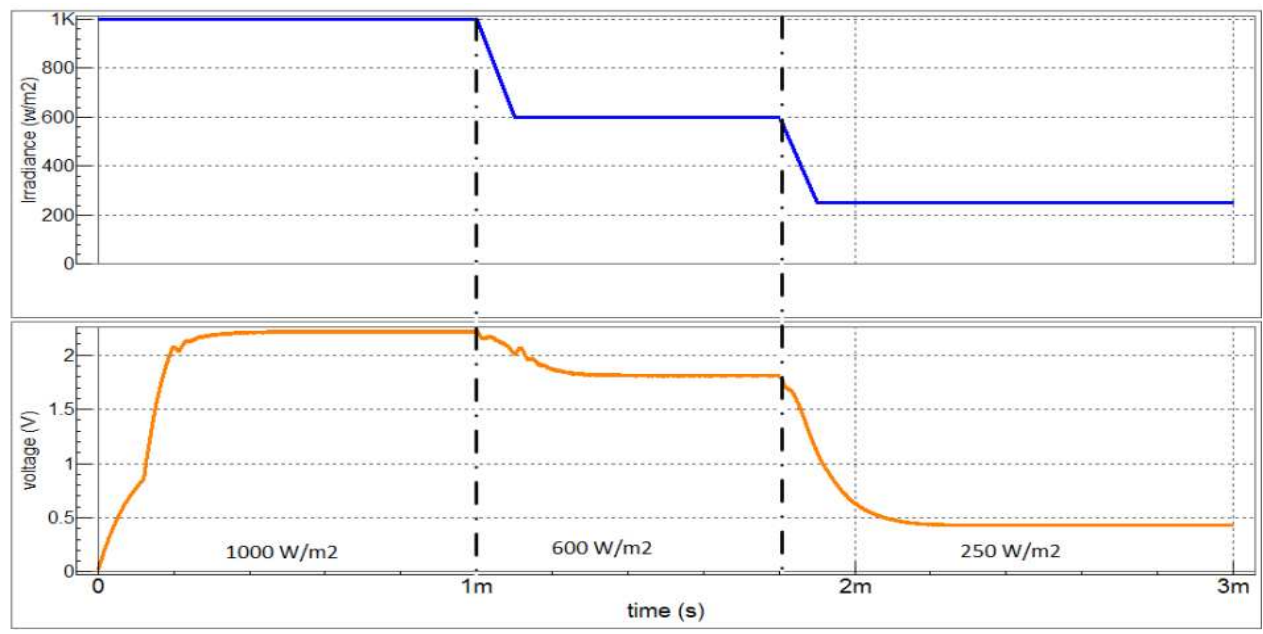

Fig. 29: Integrator output signal with a sudden irradiation change.

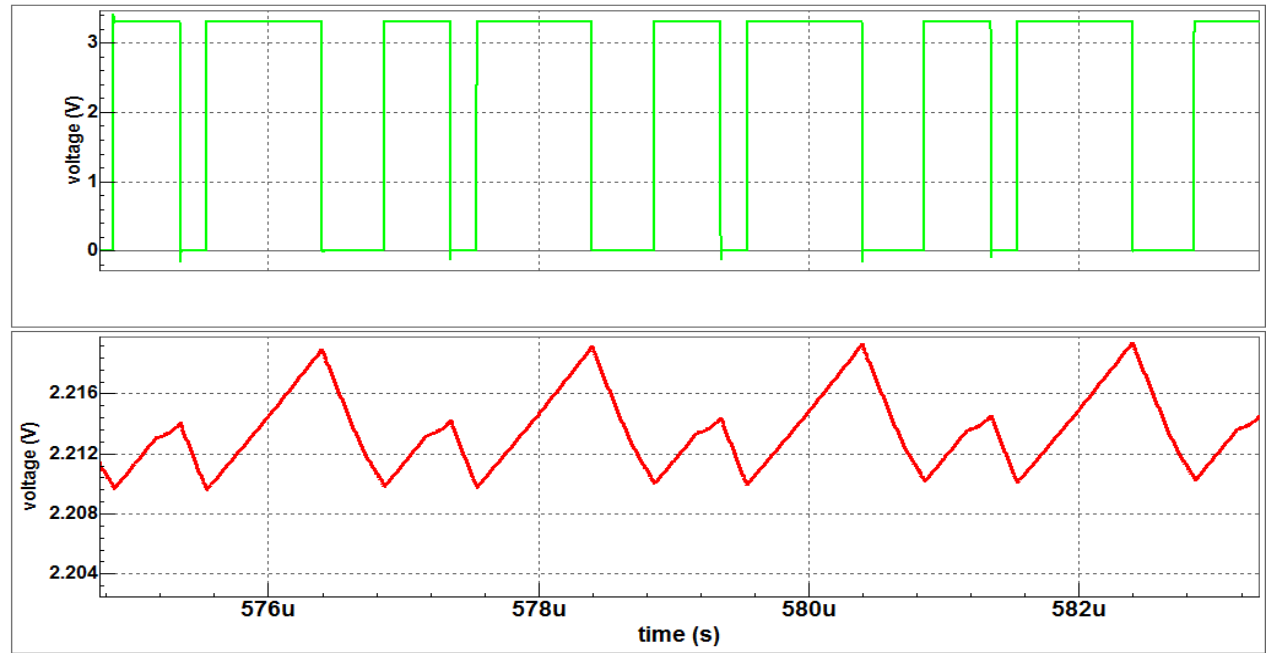

Fig. 30: Input and the output of the integrator circuit.

Fig. 31 shows the input and the output signals of the PWM circuit. The generated sawtooth signal is compared with a DC level voltage which is the output signal of the integrator circuit as shown in the upper trace of Fig. 31. The lower trace is the output signal of the comparator, which is the input to the gate drive circuit. Fig. 32 shows the output signals of the gate drive circuit that drives the two power transistors. 


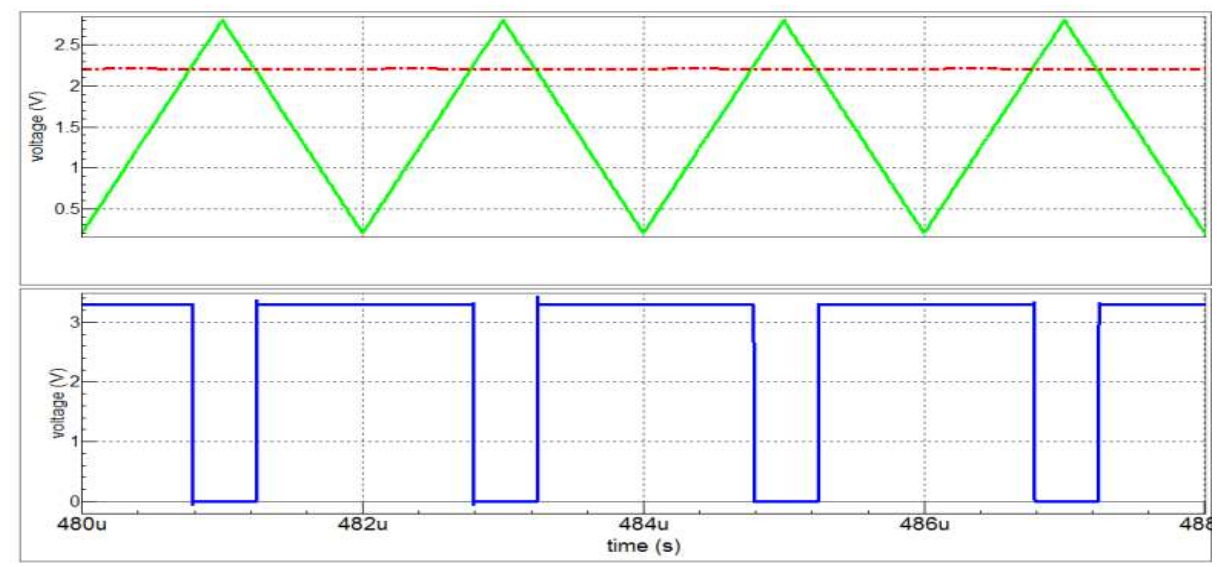

Fig. 31: The input and the output signals of the PWM circuit.

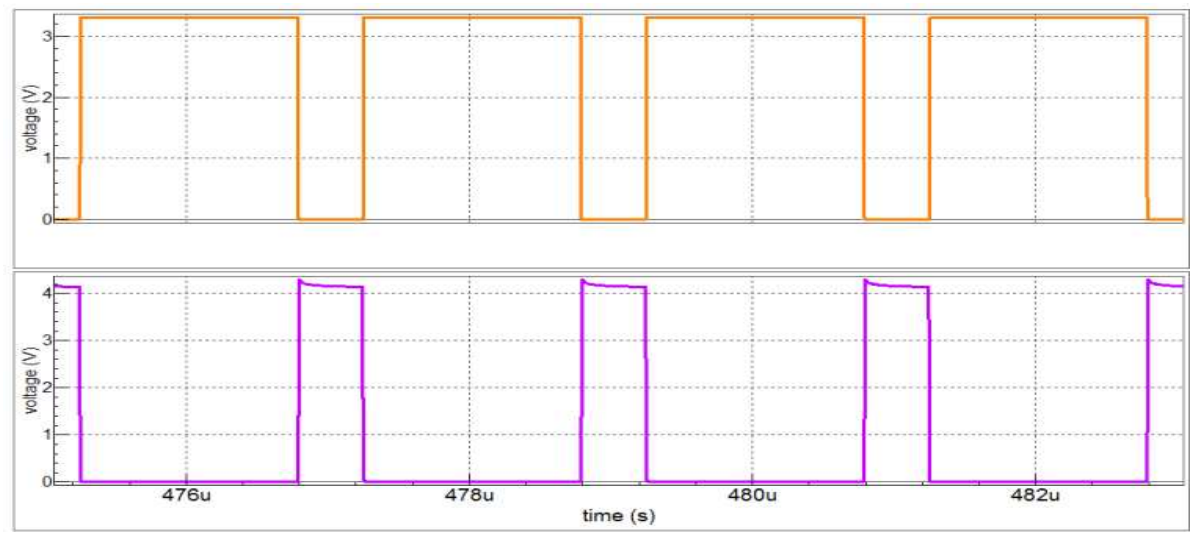

Fig. 32: The two output signals of the gate drive circuit.

The overall system has been simulated under different irradiation levels to confirm that the proposed PM-MPPT circuit and system perform as expected. Fig. 33 shows the simulation results for the cell voltage and the output voltage at three different irradiation levels, 1000, 600 and $250 \mathrm{~W} / \mathrm{m}^{2}$. Fig. 34 shows the waveforms for the input and output powers of the synchronous boost converter at the same simulated irradiation levels. The selected marked numerical values on Fig. 33 and Fig. 34 are the average values of each signal. By comparing the results in Fig. 33 and Fig. 34 with the P-V curve and the V-I curve of the PV cell, which are shown in Fig. 35, it is clear that the proposed PM-MPPT circuit correctly tracks the proper MPP over different irradiation levels. Fig. 36 shows the MPPT tracking efficiency, boost converter circuit efficiency, and the efficiency of the complete PM-MPPPT circuit. It has a tracking efficiency above $99 \%$. The total system peak efficiency is higher than $92 \%$. 


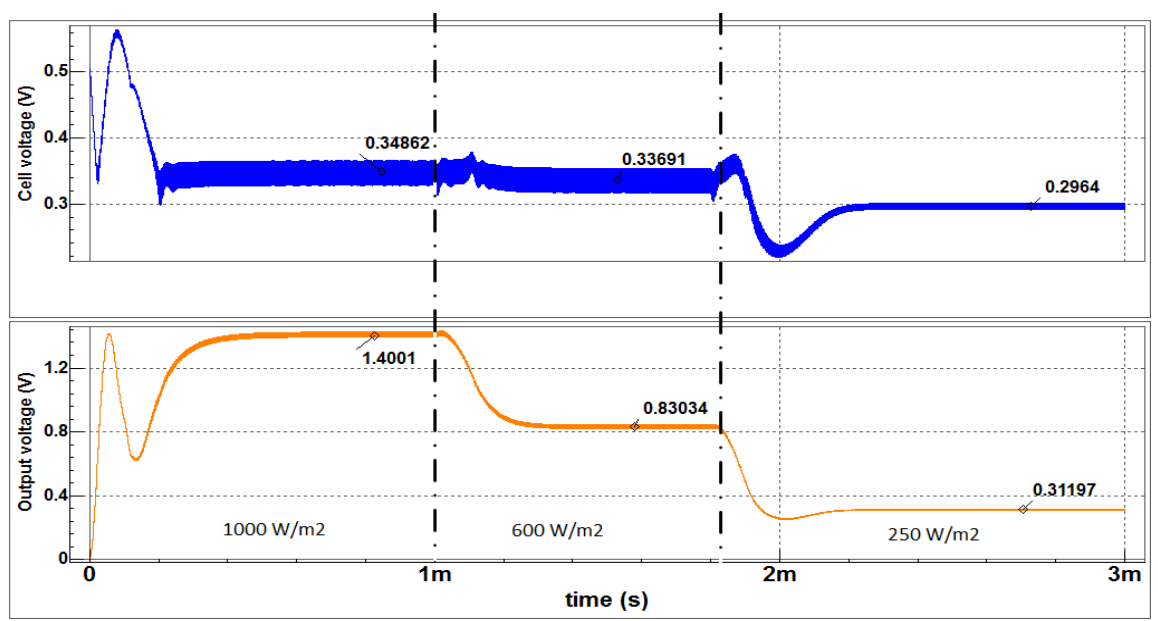

Fig. 33: Input and output voltages of the boost converter circuit under different irradiations.

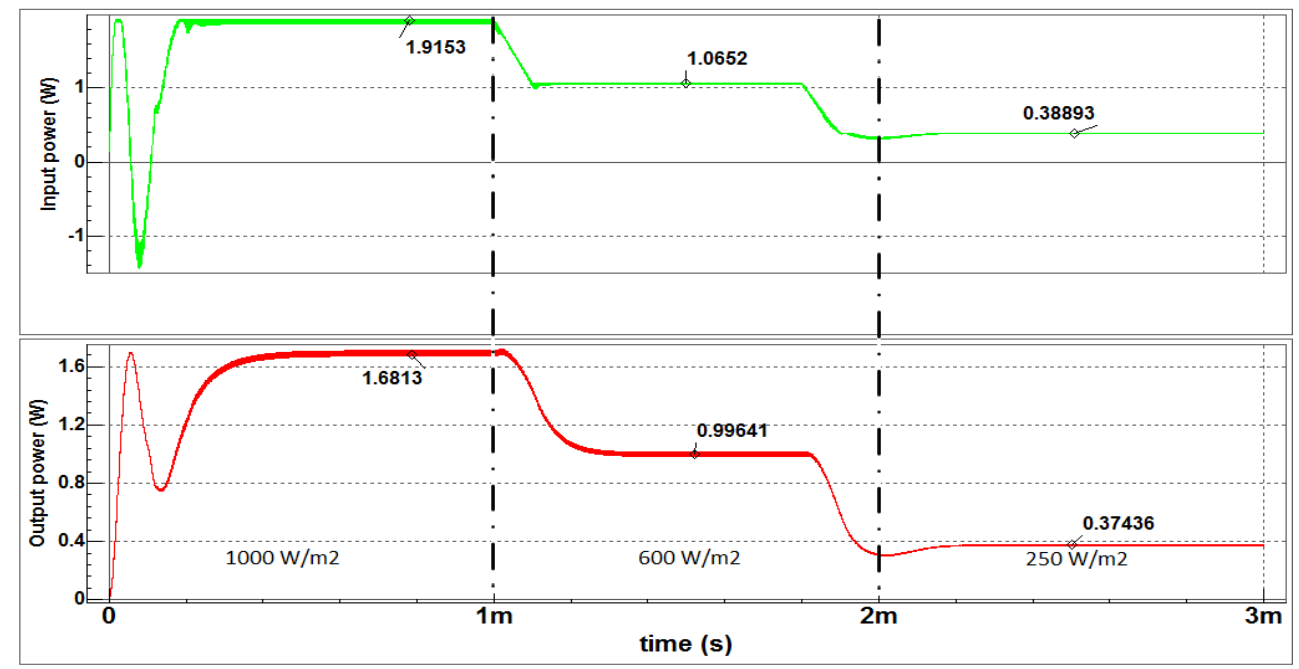

Fig. 34: Input power and output power under different irradiations.
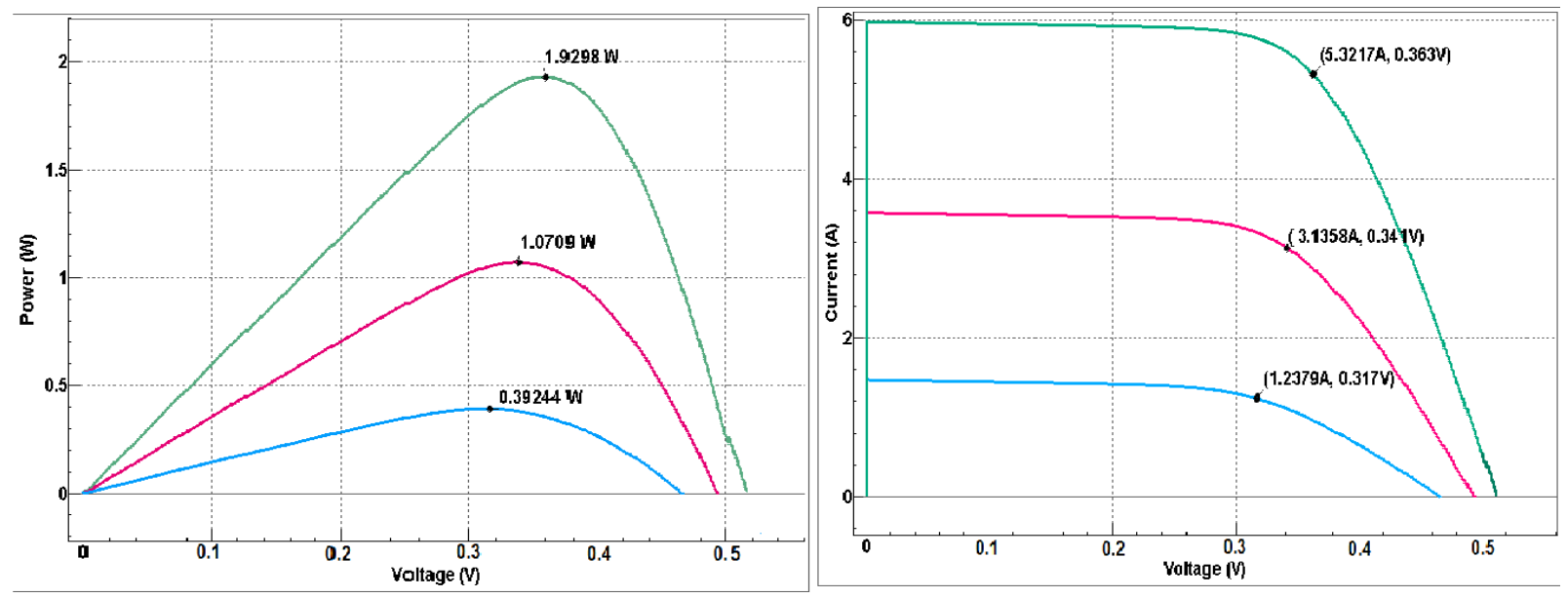

Fig. 35: P-V curve and V-I curve of the PV cell. 


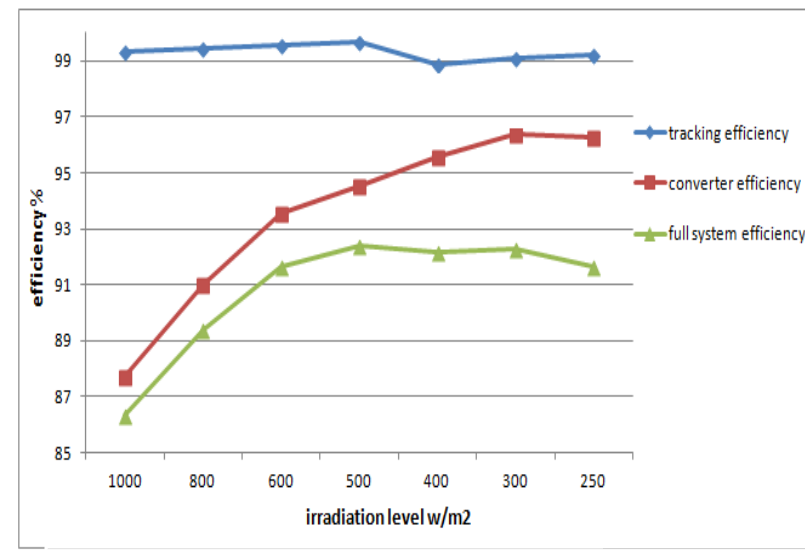

Fig. 36: Tracking efficiency, converter efficiency, and full system efficiency of PMMPPT circuit.

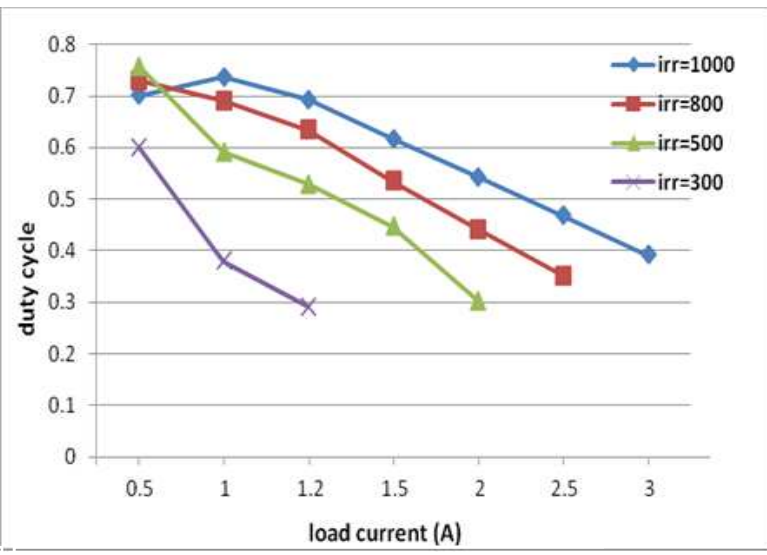

Fig. 37: Duty cycle versus load current at different irradiation levels (IR).

\section{B. Full System MPP Convergence Regions and Stability Study for the Proposed PM-MPPT Circuit}

It is important to study the system convergence regions in order to select the optimum load current that maximizes the system efficiency and covers a wide range of irradiance variation range. The MPPT circuit ensures that the converter circuit generates the cell maximum power with both load current and irradiation changes. The boost converter topology increases the cell voltage. As a result, the converter output current is lower than the input current from the solar cell. At fixed load current, there is a boundary region for the irradiation change while still achieving MPP convergence. The input current should always be higher than the load current. In this work, a boundary study is conducted for the PV system in order to identify the optimum load current that the system can deliver under the irradiation variations. Fig. 37 illustrates that under high irradiation level $\left(300 \mathrm{~W} / \mathrm{m}^{2}-1000 \mathrm{~W} / \mathrm{m}^{2}\right)$, the power converter can deliver a high load current of $3 \mathrm{~A}$. With reduced irradiation level, the maximum load current that the power converter can deliver will decrease.

The system efficiency is another important factor. Fig. 38 shows the relationship between the system efficiency and the load current. The irradiation range that the system can cover is determined by the duty cycle, load current and efficiency.

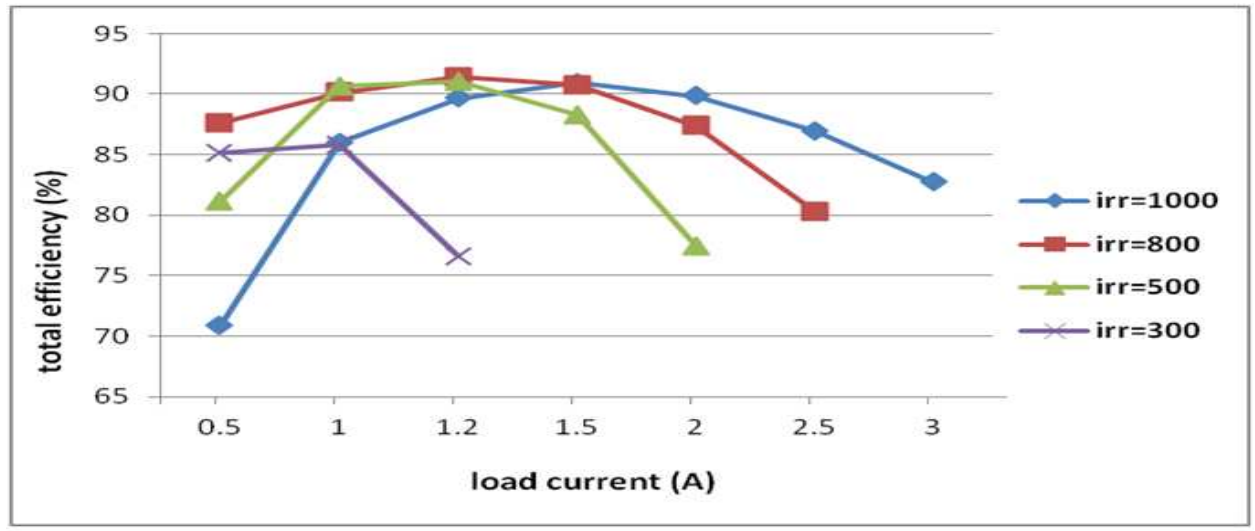

Fig. 38: System efficiency with load current at different irradiation level (IR). 
Reducing the load current increases the irradiation range but it decreases the efficiency and vice versa. The load current should be optimized at a maximum efficiency with a maximum range of irradiation. As a tradeoff between system efficiency, irradiance variation range and duty cycle range, the load current is selected to be $1.2 \mathrm{~A}$ for the specific design in this work.

On the other hand, the system stability is studied in order to determine the desired operating region under all operating conditions including environmental conditions. RCC control requires all control blocks to be unsaturated in order to keep the response action active with any irradiation level or load step change. The integrator gain is very important factor as it determines the duty cycle step. If the gain is selected to be too low, the system response will be very slow and the conversion time will be long. On the other hand, if the integrator gain is selected to be too high, the duty cycle step will be high and the system can be unstable under any change in the step response. Also, the input ripple is adjusted to make the system work in the stable rejoin. The selection of the integrator gain is carried out by simulating the system under different values of the integrator gain and recoding the conversion time. The proposed system is simulated for irradiance change from 300 to $1000 \mathrm{~W} / \mathrm{m}^{2}$ and the convergence time is recorded for different values of the integrator gain at fixed value of the switching frequency of $500 \mathrm{kHz}$ and input voltage ripple of $60 \mathrm{mV}$. Fig. 39 (a) shows that convergence time is decreased exponentially with the increase in the integrator gain. However, no appreciable improvement in convergence time is obtained at higher gain and the system becomes unstable when the gain is too high. It is considered the stability limit [36]. Also, it is clear that duty cycle step increases as the integrator gain increases. Figure 39 (b) shows the conversion time versus the change on the duty cycle step. It is clear that a value of 0.1 for the duty cycle step is the limit for the conversion time. As shown in Fig. 39 (a) for 0.1 duty cycle step, the integrator gain is 7 . The value of the integrator gain is selected to be equal 4 for the desired operation

\section{Full System Architecture Results}

Most of the available PV systems use a bypass diode per panel or sub-panel to eliminate the shaded cell or panel. If the cell architecture is used, the system can recover the mismatched power loss from the shaded cell instead of losing it. In the proposed PM-MPPT on-chip circuit for the cell level architecture, the problem of mismatch between the cells due to the fabrication process and the non-uniform irradiance levels is eliminated by tracking the maximum power point for each cell. To evaluate the PM-MPPT circuit and system, three cells each with its PM-MPPT circuit are connected in series to construct a PV panel evaluation model as shown in Fig. 40.

Fig. 41 shows the total cell power and the total output power of the synchronous boost converter for each cell of the three cells that are connected in series. The three cells have different illumination conditions. One cell is fully illuminated and the other cells are partially shaded with different shading ratios. As shown in Fig. 41, the cell under full illumination gives its own maximum power, while the other cells under partial shadow deliver the maximum 
power that can be generated. The shaded cells do not affect the operation of the fully illuminated cell. As a result, each cell will generate its own maximum power.

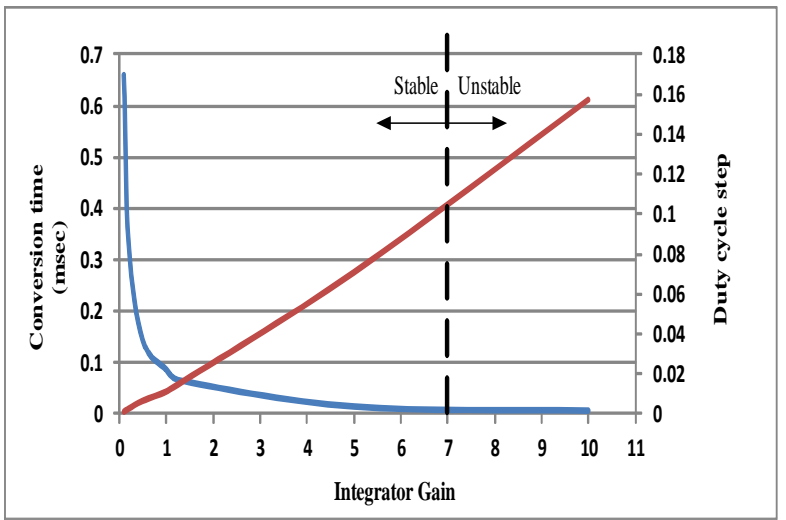

(a) The integrator gain vs. conversion time \& duty cycle step change.

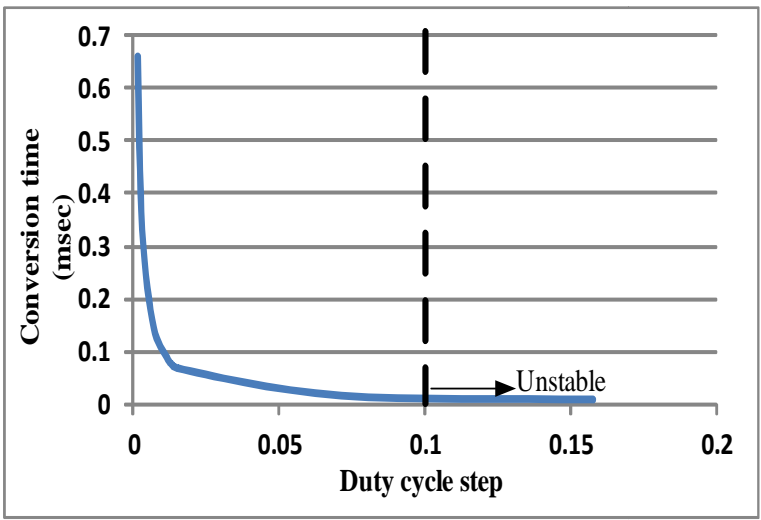

(b) The conversion time vs. duty cycle step change.

Fig. 39: Stability definition based on the integrator gain.

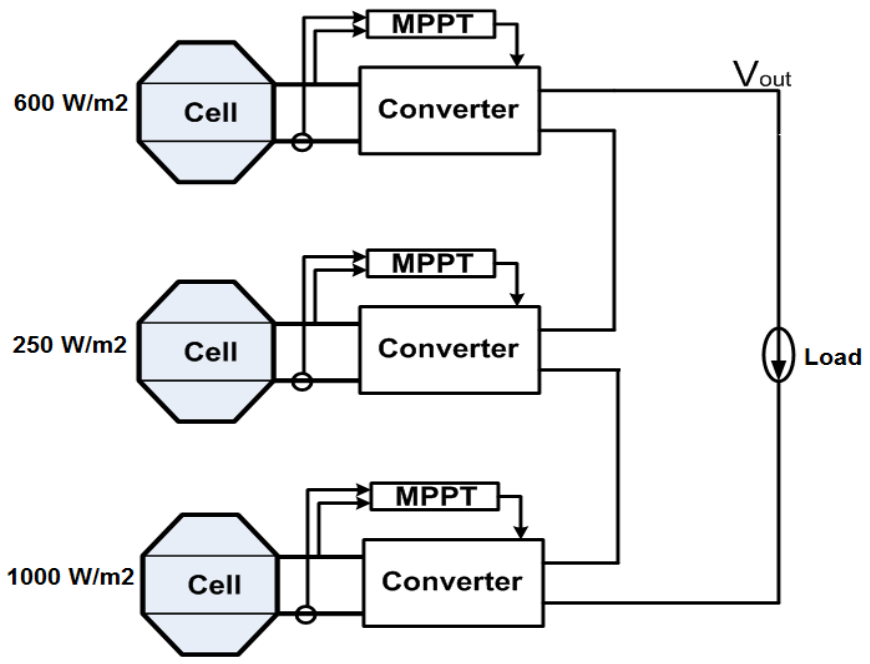

Fig. 40: The series connection of three PV cells with PMMPPT circuit per cell. 


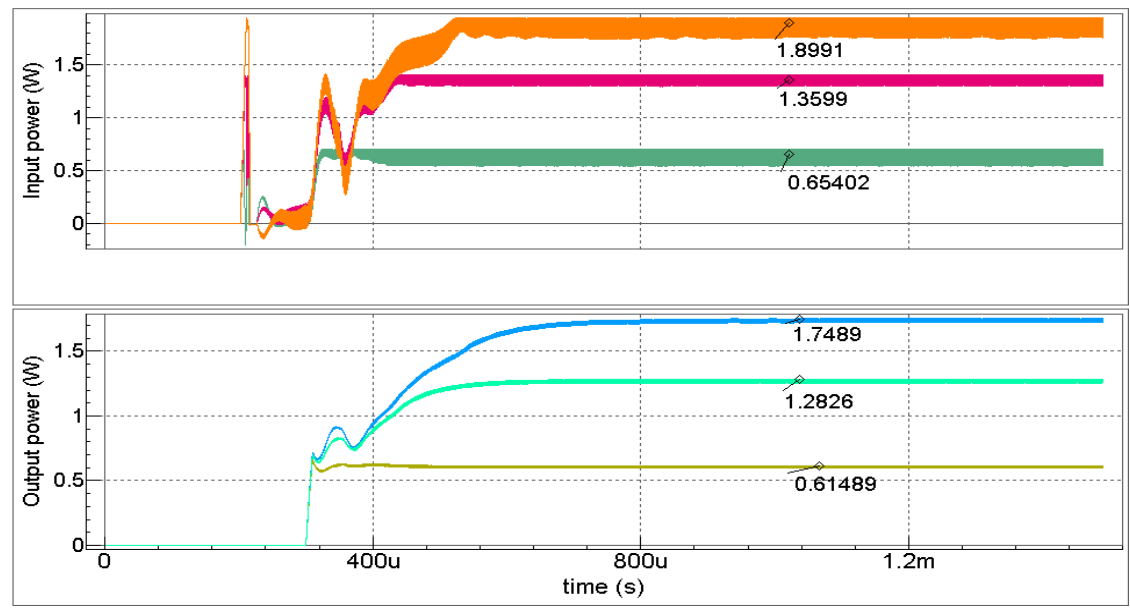

Fig. 41: The output power of each cell.

\section{ON-CHIP SYSTEM LAYOUT AND COMPARISON}

The IC layout of the overall on-chip power management circuit and system is illustrated in Fig. 42. It has an area of $2400 \mu \mathrm{m} \times 5000 \mu \mathrm{m}$. It is designed using a $0.35 \mu \mathrm{m}$ CMOS technology. Table 2 presents the area of each part of the chip. Table 3 compares the proposed PM-MPPT IC design with existing on-chip MPPT circuit designs.

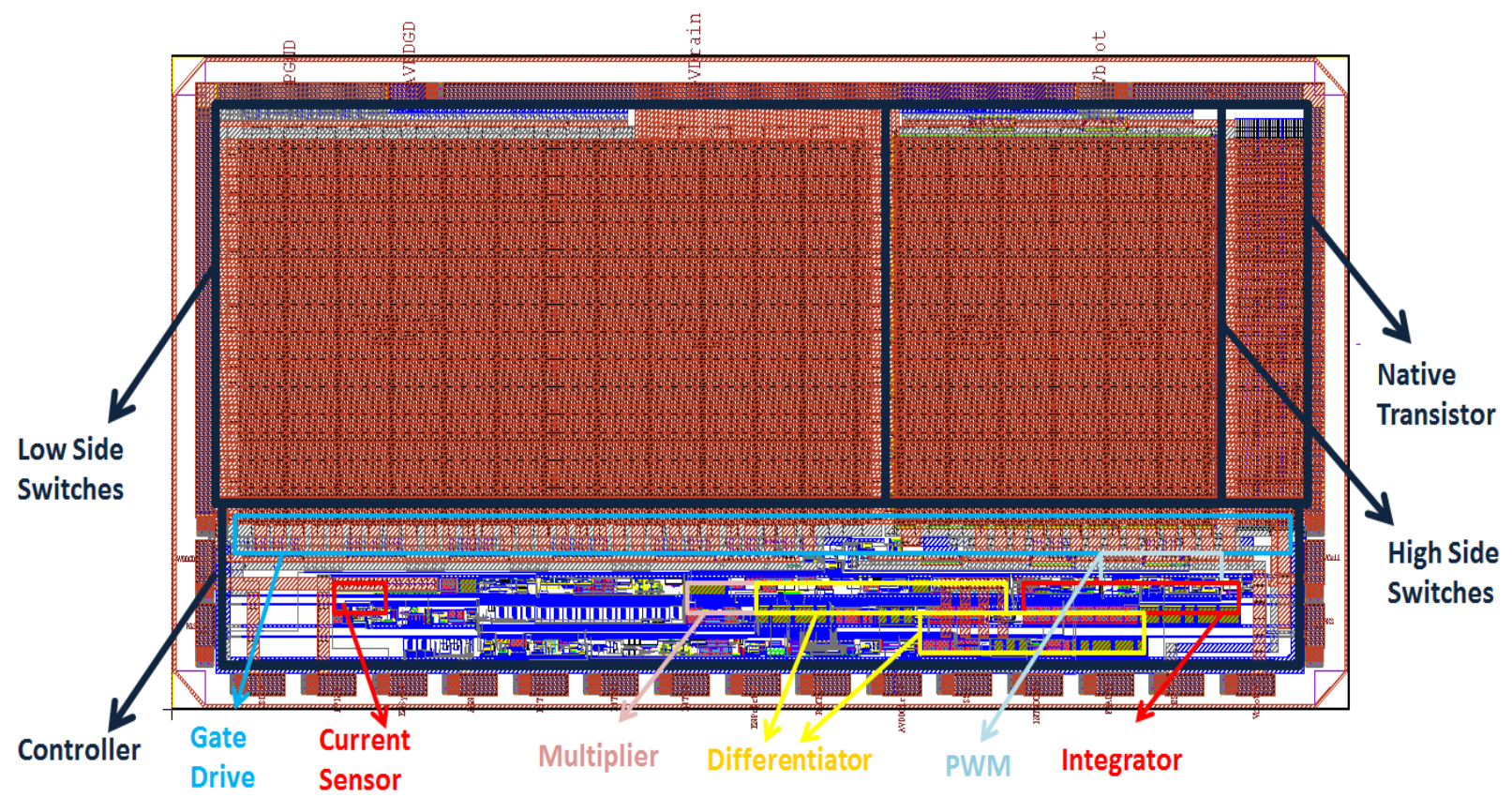

Fig. 42: The layout of the proposed PM-MPPT IC. 
Table 2: The size of different components of the integrated power converter circuit

\begin{tabular}{|c|c|}
\hline Part & Size $\left(\mathrm{mm}^{2}\right)$ \\
\hline Power MOSFET M1 & 1.299 \\
\hline Power MOSFET M2 & 1.025 \\
\hline Control circuit & 0.453 \\
\hline Overall system & 2.925 \\
\hline
\end{tabular}

The PM IC in [32] is only able to manage a small power with low peak efficiency. Another circuit in [33] is able to operate with higher power than [32] but the size is very large. The chip area in [34] is very large due to onchip $2.45 \mathrm{nF}$ capacitors. By comparing [34] and [35], although higher operating power and voltage can be achieved in [35], the system efficiency is decreased. In [35], higher peak efficiency can be achieved but the nominal operating power is low. The PM circuit in [36] is able to operate with a nominal power of $300 \mathrm{~mW}$ and a peak efficiency of $95.5 \%$. However, in [36] a thermal photovoltaic array was used to provide an input voltage of $1.3 \mathrm{~V}$. The proposed PM-MPPT circuit and system in this work is able to operate with the lowest input voltage and the highest output power compared with the ICs in [32-36] and achieves efficiency of 92.3\%. Also, the proposed PM-MPPT IC has the smallest size under $2 \mathrm{~W}$ nominal power level with higher power density. The basic P\&O MPPT algorithm used in $[32-34,36]$ has slower response/convergence time because the power stage control signal is much slower than the power stage switching frequency. For instance, the update control signal in [32] is one tenth of the switching frequency. The control algorithm in [33] has a mode called "long wait", in which the power stage control variable is kept constant. If any transient occurs during this mode, the MPPT controller will not respond. In the proposed PMMPPT IC, RCC controller is used, which is able to update the control signal as fast as the power stage switching frequency $(500 \mathrm{kHz}$ in this work). Another drawback of the conventional $\mathrm{P} \& \mathrm{O}$ algorithm implementation is a complicated digital design. In [35] and [36], register circuit, counter circuit, accumulator circuit, DPWM circuit and DAC (digital-to-analog converter) circuit are needed which increase the chip area. On the other hand, in the proposed circuit, only analog logic gates are needed for the RCC control circuit. The RCC controller is able to achieve two advantages over the conventional P\&O controllers: faster tracking speed and reduced circuit complexity in the design and integration processes.

\section{CONCLUSION}

In this paper, an on-chip PM-MPPT circuit and system are presented in order to harness the PV power in cell level architecture with higher efficiency, faster tracking speed, and smaller chip size (achieved by on-chip integration). Cell level PM-MPPT circuit has addressed the issue of partial shading effect and mismatch effect between PV solar cells. Using the proposed on-chip integrated power management circuit with the distributed MPPT system, the shaded cells produce their own maximum power without affecting the illuminated cells. The challenge of integrating the complete circuit building blocks on the same IC in order to control a $2 \mathrm{~W}$ cell and has a high 
efficiency of $92 \%$ has been achieved in this paper. The PV cell with the attached PM-MPPT circuit acts as a DC generator. The output power depends only on the received irradiance. The control circuit design and implementation, convergence study, stability study and the on-chip layout are presented in this paper. A comparison between the proposed system and existing IC systems is also presented. Future work includes, but is not limited to, the PM-MPPT IC fabrication, testing and the experimental development and testing of the series-connected PV cells system using the developed PM-MPPT IC power module.

Table 3: A comparison between the proposed PM-MPPT IC design and existing on-chip MPPT circuit designs.

\begin{tabular}{|c|c|c|c|c|c|c|}
\hline Specifications & [32] & [33] & [34] & {$[35]$} & [36] & This work \\
\hline process & $\begin{array}{l}0.35 \mu \mathrm{m} \\
\mathrm{CMOS}\end{array}$ & $0.35 \mu \mathrm{m}$ CMOS & $\begin{array}{l}0.25 \mu \mathrm{m} \\
\mathrm{CMOS}\end{array}$ & $\begin{array}{l}0.35 \mu \mathrm{m} \\
\mathrm{CMOS}\end{array}$ & $\begin{array}{l}0.35 \mu \mathrm{m} \\
\text { CMOS }\end{array}$ & $\begin{array}{l}0.35 \mu \mathrm{m} \\
\mathrm{CMOS}\end{array}$ \\
\hline Input voltage & $2.1-3.5 \mathrm{v}$ & $>0.6 \mathrm{v}$ & $0.5-2 \mathrm{v}$ & $1-2.7 \mathrm{v}$ & $0.8-1.3 \mathrm{~V}$ & $<0.5 \mathrm{~V}$ \\
\hline Output voltage & $3.6-4.4 \mathrm{v}$ & $0-3.3 \mathrm{v}$ & $0-5 v$ & $2 \mathrm{v}$ & $3.6-4.2 \mathrm{~V}$ & $0.5-2 \mathrm{~V}$ \\
\hline Nominal power & $<780 \mu \mathrm{W}$ & $10 \mu \mathrm{W}-1 \mathrm{~mW}$ & $5 \mu \mathrm{W}-10 \mathrm{~mW}$ & $0-80 \mu \mathrm{W}$ & $300 \mathrm{~mW}$ & $2 \mathrm{~W}$ \\
\hline Efficiency & $\begin{array}{c}67 \% \\
@ 529 \mathrm{uW}\end{array}$ & $70 \%$ & $\begin{array}{c}70 \% \\
\text { @ 16uW }\end{array}$ & $\begin{array}{c}86 \% \\
@ 35 \mathrm{uW}\end{array}$ & $95.4 \%$ & $92.3 \%$ \\
\hline Chip area $\left(\mathrm{mm}^{2}\right)$ & 0.62 & 59 & 23.06 & 22.9 & 1.159 & 2.925 \\
\hline $\begin{array}{c}\text { MPPT Algorithm } \\
\text { Features }\end{array}$ & $\begin{array}{l}\mathrm{P} \& \mathrm{O} \\
\mathrm{MPPT}\end{array}$ & $\begin{array}{c}\text { Without Real- } \\
\text { time } \\
\text { MPPT }\end{array}$ & $\begin{array}{r}\mathrm{P} \& \mathrm{O} \\
\mathrm{MPPT}\end{array}$ & $\begin{array}{l}\mathrm{P} \& \mathrm{O} \\
\mathrm{MPPT}\end{array}$ & $\begin{array}{l}\mathrm{P \& O} \\
\mathrm{MPPT}\end{array}$ & $\begin{array}{c}\text { RCC } \\
\text { MPPT }\end{array}$ \\
\hline
\end{tabular}

\section{ACKNOWLEDGMENT}

This work is sponsored in part by the Egyptian Science and Technology Development Funds (STDF) under STDF project \#1954 and the U.S. Department of Agriculture (USDA) under USDA Project \#58-3148-0-204. Any opinions, findings, and conclusions or recommendations expressed in this material are those of the author(s) and do not necessarily reflect the views of the funding agencies.

\section{REFERENCES}

[1] A. Askarzadeh and A. Rezazadeh "Extraction of maximum power point in solar cells using bird mating optimizer-based parameters identification approach," Solar Energy, vol. 90, pp. 123-133, April 2013.

[2] A.-A. Bayod-Rújula and J.-A. Cebollero-Abián, "A novel MPPT method for PV systems with irradiance measurement," Solar Energy, vol. 109, pp. 95-104, Nov. 2014.

[3] A. Mellit, H. Rezzouk, A. Messai, B. Medjahed, "FPGA-based real time implementation of MPPT controller for photovoltaic systems" Renewable Energy, 36 (2011), pp. 1652-1661.

[4] Al-Atrash H, Batarseh I, Rustom K, "Statistical modeling of DSP-based Hill-climbing MPPT algorithms in noisy environments" In: Proc. of Applied Power Electronics Conference and Exposition, IEEE, vol.3, Austin, Texas, USA; 2005. p. 1773-7. 
[5] M. A. Elgendy, B. Zahawi and D. J. Atkinson, “ Assessment of Perturb and Observe MPPT Algorithm Implementation Techniques for PV Pumping Application" IEEE Transactions on Sustainable Energy, VOL. 3, NO. 1, Jan 2012.

[6] D. Lalili, A. Mellit, N. Lourci, B. Medjahed, E.M. Berkouk, Input output feedback linearization control and variable step size MPPT algorithm of a grid-connected photovoltaic inverter, Renewable Energy 36(2011), pp. 3282-3291.

[7] T.P. Corrêa, S.I. Seleme Jr and S.R. Silva, Efficiency optimization in stand-alone photovoltaic pumping system, Renewable Energy 41(2012), pp. 220-226.

[8] V. Vaidya and D. Wilson, Maximum power tracking in solar cell arrays using time-based reconfiguration, Renewable Energy 50(2013), pp. 74-81.

[9] Y.-H. Liu, J.-H. Chen and J.-W. Huang, "Global maximum power point tracking algorithm for PV systems operating under partially shaded conditions using the segmentation search method," Solar Energy, vol. 103 (2014), pp. 350-362.

[10] W. Herrmann, W. Wiesner, W. Vaaben " Hot Spot Investigation On PV Modules-New Concepts For A Test Standard And Consequences For Module Design With Respect To Bypass Diodes" Photovoltaic Specialist Conference, IEEE 26, Oct 1997.

[11] A. S. Masoum, F. Padovan, M. A. S. Masoum "Impact of Partial Shading on Voltage-and Current Based Maximum Power Point Tracking of Solar Modules" Power and Energy Society General Meeting, June 2010 IEEE.

[12] K. Kobayashi, I. Takano and Y. Sawada, A study on a two stage maximum power point tracking control of a photovoltaic system under partially shaded insolation conditions, in IEEE Power Eng. Soc. Gen. Meet., 2003, pp. 2612-2617.

[13] H. Patel, V. Agarwal, "MATLAB-based modeling to study the effects of partial shading on PV array characteristics" IEEE Transactions on Energy Conversion, 23(2008), pp. 302-310.

[14] A.A. Moghaddam, A. Seifi and T. Niknam, "Multi-operation management of a typical micro-grids using Particle Swarm Optimization: A comparative study" Renewable and Sustainable Energy Reviews 16(2012), pp. 1268-1281.

[15] J. Young-Hyok, J. Doo-Yong, W. Chung-Yuen, L. Byoung-Kuk, and K. Jin-Wook, "A Real Maximum Power Point Tracking Method for Mismatching Compensation in PV Array Under Partially Shaded Conditions,” IEEE Trans. Power Elctron., vol. 26, no. 4, pp. 1001-1009, Apr. 2011.

[16] T. L. Nguyen and K. S. Low, "A Global Maximum Power Point Tracking Scheme Employing DIRECT Search Algorithm for Photovoltaic Systems,” IEEE Trans. Ind. Electron., vol. 57, no. 10, pp. 3456-3467, Oct. 2010.

[17] A. Bidram, A. Davoudi and R. S. Balog, "Control and Circuit Techniques to Mitigate Partial Shading Effects in Photovoltaic Arrays" IEEE Journal of Photovoltaics, vol. 2, no. 4, pp. 532-546, Oct. 2012.

[18] Q. Li, P. Wolfs "A Review of the Single Phase Photovoltaic Module Integrated Converter Topologies with Three Different DC Link Configurations" IEEE Transactions on Power Electronics, VOL 23, NO 3, May 2008.

[19] J.S. Christy Mano Raj, A. Ebenezer Jeyakumar, "A two stage successive estimation based maximum power point tracking technique for photovoltaic modules," Solar Energy,vol. 103, pp. 43-61, May 2014.

[20] K.M. Tsang, W.L. Chan and X. Tan, "PLL-less single stage grid-connected photovoltaic inverter with rapid maximum power point tracking," Solar Energy, vol. 97, pp. 285-292, November 2013.

[21] A. Hassan, E. Abdelkarem, M. E. Ahmed, M. Orabi, Y. Jiang, and J. Abu Qahouq, "Single Cell Photovoltaic with Integrated Converter" IEEE International Telecominication Energy Conference (INTELEC) 2011.

[22] A. K. Das, " An explicit J-V model of a solar cell using equivalent rational function form for simple estimation of maximum power point voltage," Solar Energy, vol. 98, pp. 400-403, December 2013.

[23] Y. M. Roshan and M. Moallem, "Maximum power point estimation and tracking using power converter input resistance control," Solar Energy, vol. 96, pp. 177-186, October 2013.

[24] A. Shawky, F. Helmy, M. Orabi, J. Abu Qahouq, Z. Dang, “ On chip integrated Cell-Level power management Architecture with MPPT for PV soalr System" in the proceeding of the IEEE Applied Power Electronics Conference, APEC, March 2014.

[25] T. Esram, J.W. Kimball, P.T. Krein, P.L. Chapman, P. Midya, "Dynamic maximum power point tracking of photovoltaic arrays using ripple correlation control," IEEE Transactions on Power Electronics, 21(2006), pp. 1282-1291

[26] K. R. Laker, W. M. C. Sansen, "Design of Analog Integrated Circuits and Systems” McGraw-Hill, Inc.

[27] R. W. Ericson, D. Maksimovic, " Fundamentals of Power Electronics," Kluwer Academic Publishers, Inc 2004. 
[28] F. C. Lee, Q. Li, “High Frequency Integrated Point-of-Load Converters: Overview,” IEEE Trans. Power Electron., vol. 28, no. 9, pp. 41274136, Sept. 2013.

[29] M. Orabi, A. Abou-Alfotouh, A. Lofty, " $\mathrm{C}_{\text {oss }}$ capacitance contribution to synchronous buck converter losses" IEEE power electroic specialist conf, PESC 2008, pp. 666-672.

[30] M. L. Chiu and H. P. Chou, "An on-chip current sensing technique for hysteresis current-controlled boost converters", IEEE PEDS.

[31] Z. Li and C. Chen, "Low power low-noise CMOS analogue multiplier," IEEE Proc. Circuit Devices Syst., Vol. 153, No. 3, June 2006.

[32] H. Shao, C. Y. Tsui, and W. H. Ki, "The design of a micro power management system for applications using photovoltaic cells with the maximumoutput power control,” IEEE Trans. Very Large Scale Integr. (VLSI) Syst.,vol.17, no.8, pp. 1138-1142, Aug. 2009.

[33] I. Doms, P. Merken, R. Mertens, and C. Van Hoof, "Integrated capacitivepower-management circuit for thermal harvesters with output power 10to $1000 \mu \mathrm{W}$," in Proc. IEEE Int. Solid-State Circuits Conf. Dig. Tech.Papers, pp. 300-301, Feb. 2009.

[34] Y. Qiu, C. V. Liempd, B. O. H. Veld, G. Blanken, and C. V. Hoof, $5 \mu \mathrm{W}$-to-10 mW input power range inductive boost converter for indoor photovoltaic energy harvesting with integrated maximum power point tracking algorithm, in Proc. IEEE Int. Solid-State Circuits Conf. Dig. Tech. Papers, pp. 118-120, Feb. 2011.

[35] J. Kim, K. Jihwan,and K. Chulwoo, "A Regulated Charge Pump With a Low-Power Integrated Optimum Power Point Tracking Algorithm for Indoor Solar Energy Harvesting,” IEEE Transactions on circuits \&systems-II: express briefs , vol. 58, no. 12, Decembre 2011.

[36] C.N. Robert, W. Li, I. Celanovic and D. J. Perreault, "Integrated CMOS DC-DC Converter with Digital Maximum Power Point Tracking for a Portable Thermo- photovoltaic Power Generator," in Proc. of Energy Conversion Congress and Exposition (ECCE), pp.197-204, Sept. 2011. 